\title{
The Marginal Social Cost and DeadWeight Loss of Overweight and Obesity in Iran
}

\author{
Habib Shahbazi ${ }^{1}$
}

shahbazi@sjau.c.ir

\begin{abstract}
The purpose of this study is to investigate the effect of overweight and obesity on personal medical expenses and deadweight loss in Iran; this study also measures the portion of budget imposed on the public sector due to obedity. To this end, questionnaire data were used to estimate the econometric model of factors affecting personal medical expense. Hence, the social costs (personal and public) and dead weight loss due to overweight are calculated. Data were collected from 1250 individuals in 5 provinces of Tehran, Isfahan, Fars, Hamadan and Guilan for the year 2019. Then the social costs (personal and public) and dead weight loss due to overweight are calculated. The results show that age, education, and poverty have a positive impact on personal medical expenditures; However, the poverty index has no significant impact on such expenditures. Moreover, having a history of disease in health records has positive and significant effect on personal medical expenses. Estimates of the additional cost of overweight and deadweight loss indicate an increase in the nominal value and a fluctuating increase in real value over the years under study. Thus, a one-unit increase in body mass index would increase general medical costs by $2.31 \%$. The policies in "health subsector" (such as promoting the culture of having a healthy diet), "treatment subsector" (such as offering appropriate and cheaper therapies and prevention), and in "education subsector", can help to prevent the prevalence of obesity and overweight.
\end{abstract}

Keywords: Overweight, Obesity, Public and Social Expenditure, DeadWeight Loss, Iran.

JEL Classification: I11, I15, I31. 


\section{هزينه نهايى اجتماعى و رفاه ازدسترفته ناشى از اضافه وزن و جاقى در ايران إنتمان}

shahbazi@sjau.c.ir

\author{
حبيب شهيبازى \\ استاديار دانشخاه سيدجمال الدين اسدآبادى، اسدآباد، \\ همدان ايران.

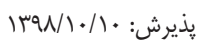 \\ دريافت:
}

קكيده: اين يروهش با هدف بررسى اثر ميزان اضافه وزن و خاقى بر هزينههاى شخصى

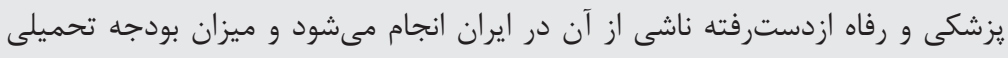

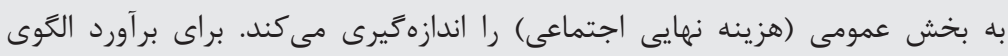

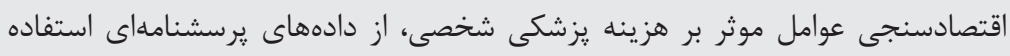

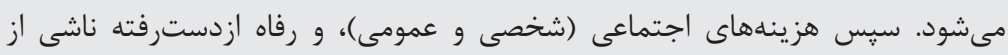

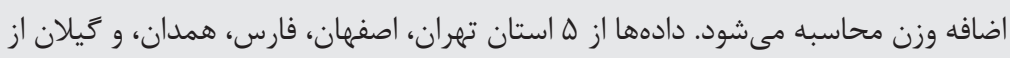

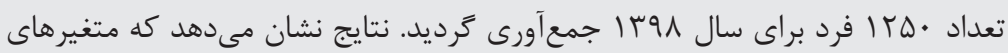

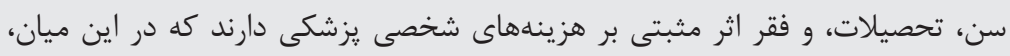

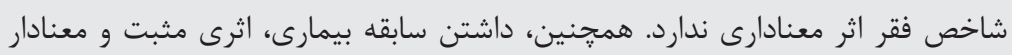

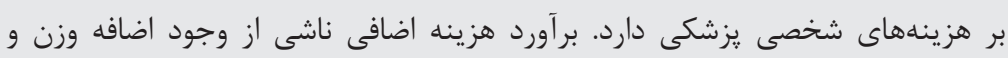

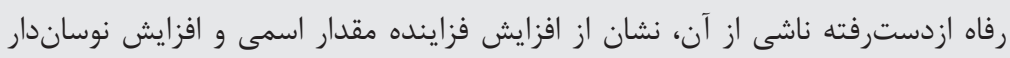

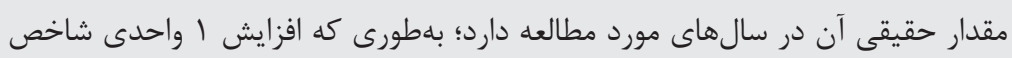

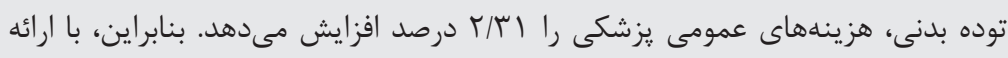

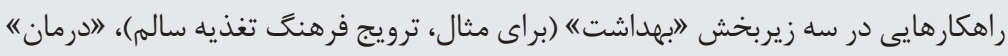

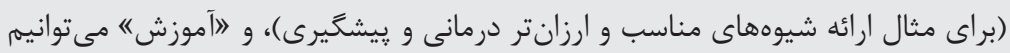

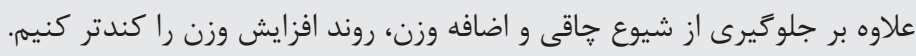

كليدوازهها: اضافه وزن، جاقى، هزينه هاى عمومى و اجتماعى، رفاه ازدسترفته، ايران. طبقدبندى I31, I15, I11 :JEL. 
يكى از معضلهاى مههم در حوزه بهداشت عمومى، بلويزه در مسائل تغذيهاى و سبك زندكى در كشورها، وجود اضافه وزن و شيوع جاقى است. بر اساس تعريف سازمان بهداشت جهانى '(19 • r)،

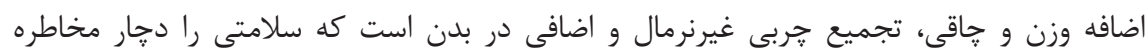
مى كند. اين يديده با شاخص توده بدنى' سنجيده مىشود كه از تقسيم وزن (برحسب كيلوكرم)

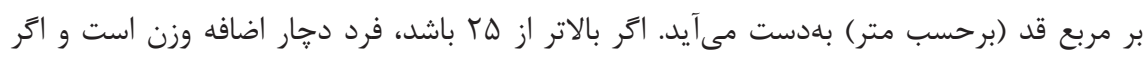

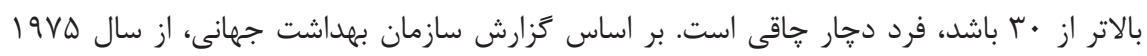

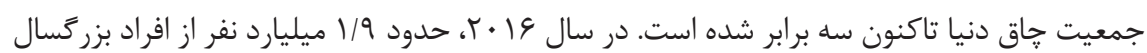

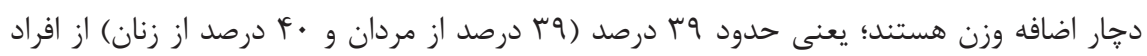

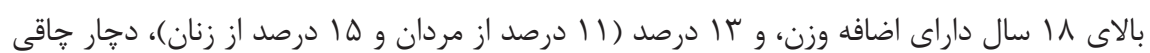

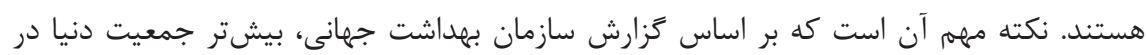

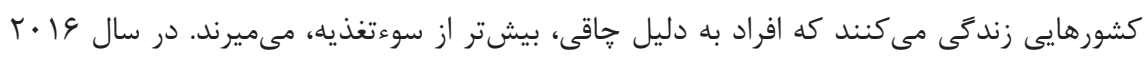

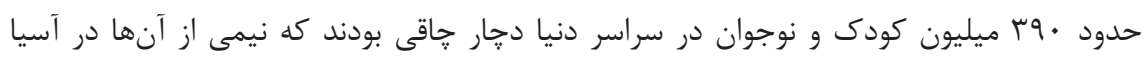

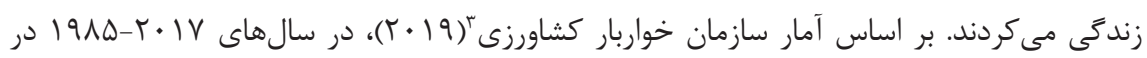

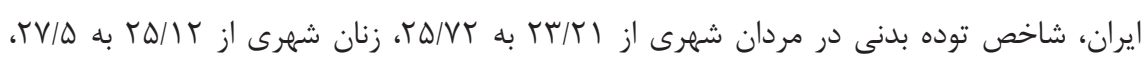

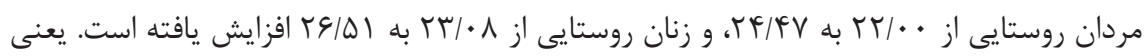

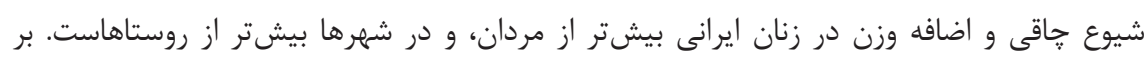

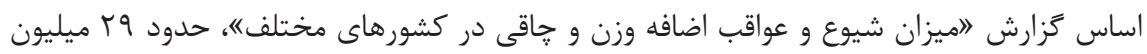

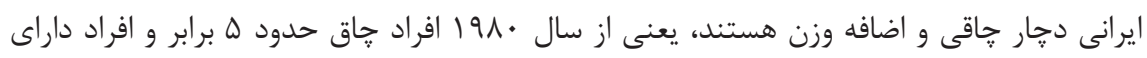

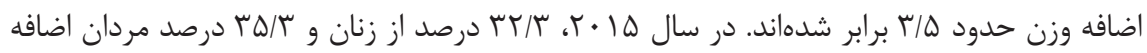

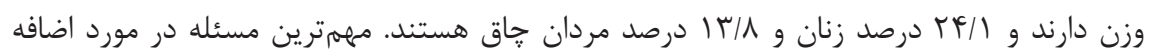

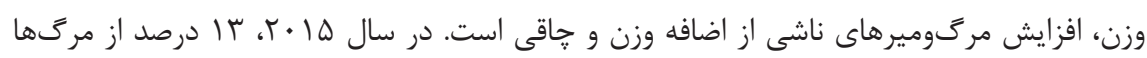

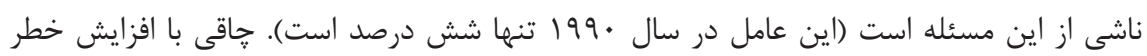

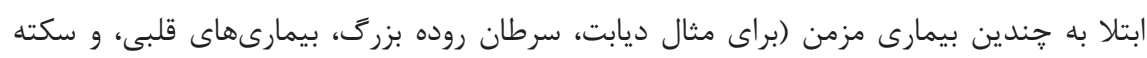

1. The International Classification of adult underweight, overweight and obesity according to BMI. 2019, from https://apps.who.int/bmi/index.jsp?introPage=intro_3.html

2. Body Mass Index (BMI)

3. Body Mass Index Report, from www.faostat.com 
مغزى) همراه است و افزايش هزينههاى مستقيم خدمات ييشگيرى، تشخيصى، و درمانى مرتبط با اين بيمارىهاى مزمن را در يى دارد (مold \& Colditz; 1998; Cawley \& Meyerhoefer, 2012;

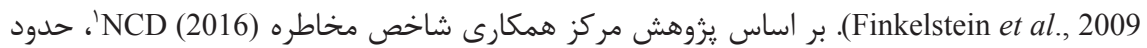

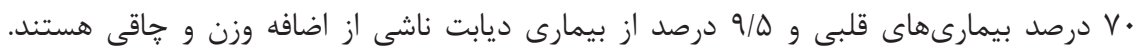

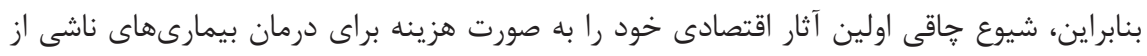

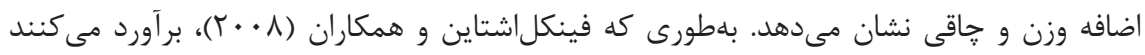

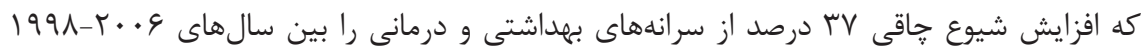
در آمريكا به خود تخصيص مى دهد. علاوه بر اين، افراد جاق سالانه

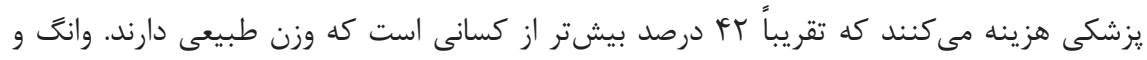

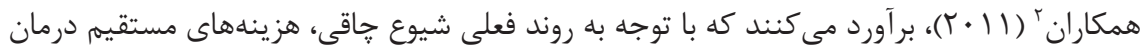

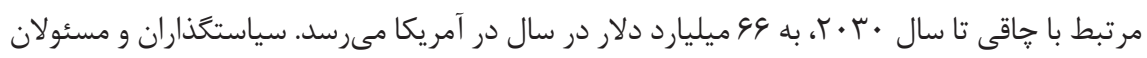
بهداشت عمومى اين افزايش هزينهها را به عنوان دليل منطقى براى سياستهايى با هدف كاهش

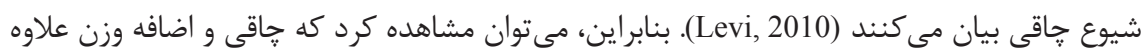
بر ايجاد هزينه بر فرد، هزينههايى را به بخش عمومى تحميل مى كند. در نتيجه، هزينههاى اجتماعى

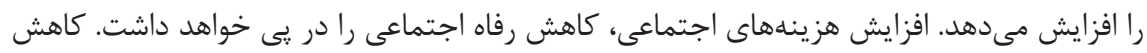

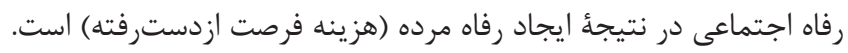

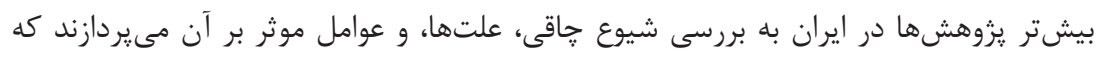

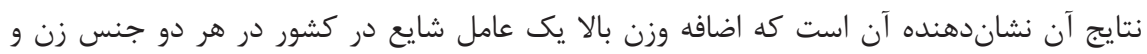

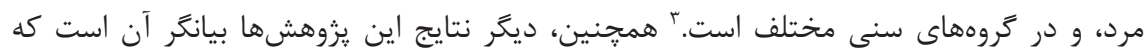

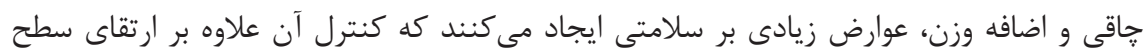

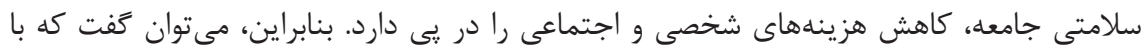
وجود يزوهشهاى فراوان در زمينه علل، عوارض، و روشهاى دهاى درمان جاقى و اضافه وزن در ايران، و و يزوهش هاى زياد در مورد هزينههاى (شخصى و اجتماعى) ناشى از وجود جاقى و اضافه وزن در دنيا،

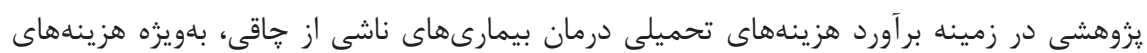

1. NCD Risk Factor Collaboration

2. Wang et al. 
اجتماعى و عمومى آن در ايران، انجام نشده است. بنابراين، اين يزوهش با هدف بررسى اثر ميزان

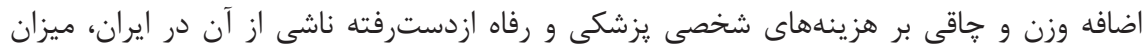

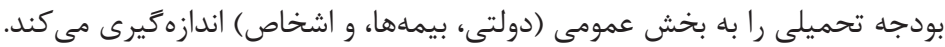

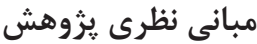

هزينه نهايى اجتماعى وجود اضافه وزن و رفاه ازدسترفته ناشى از آن شامل هزينه نهايى شخصى

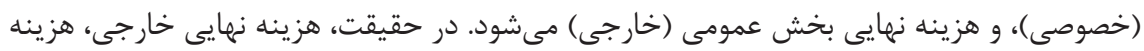

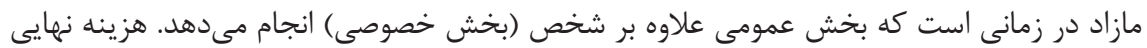

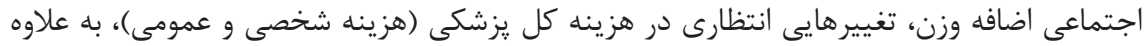

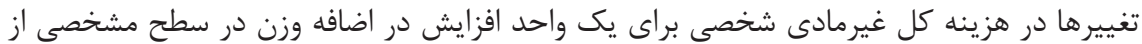

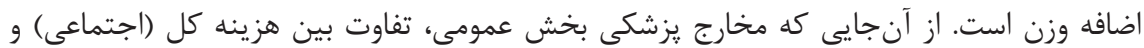

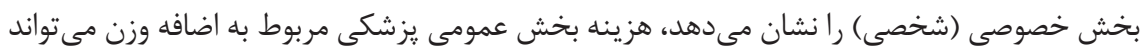

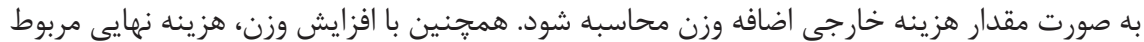

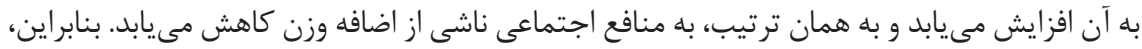

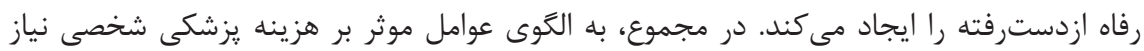

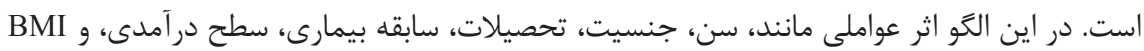

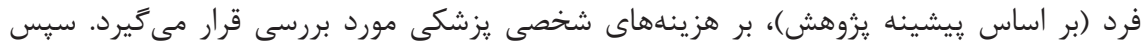

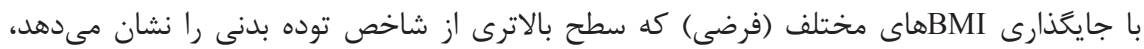

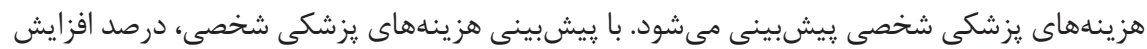

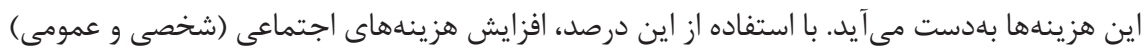

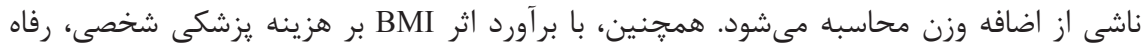

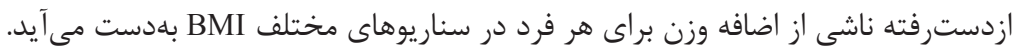

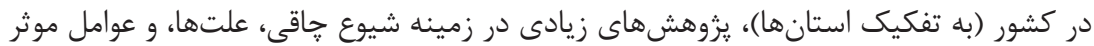

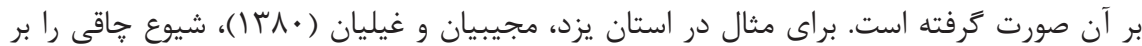

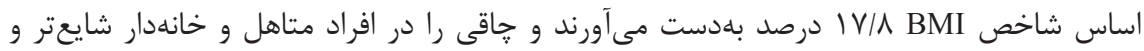

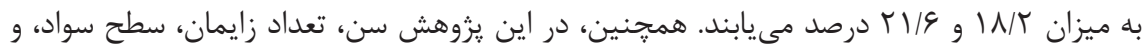

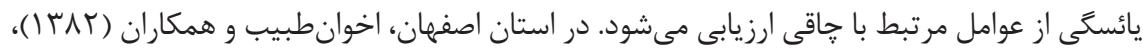




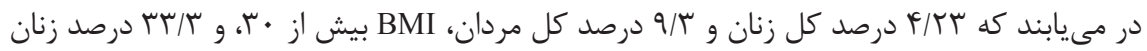

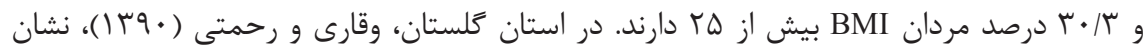
مى دهند كه بر اساس آزمون ركرسيون خطى، مقدار افزايش وزن، قد، و BMI در هر سال در يسران

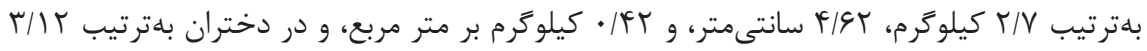

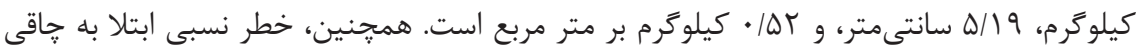

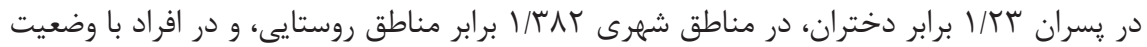

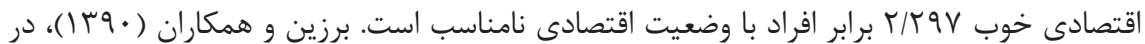

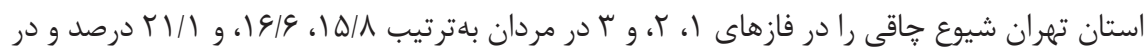

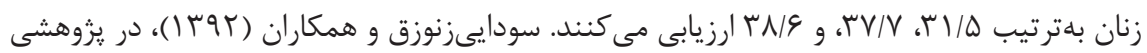
در شهرستان مرند (استان آذربايجان شرقى) نشان مىدهند كه 1/1 د درصد از دانشآموزان داراى

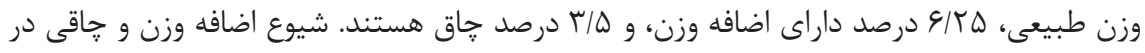

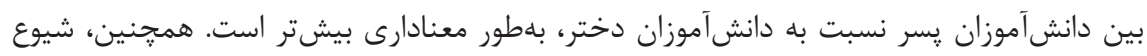

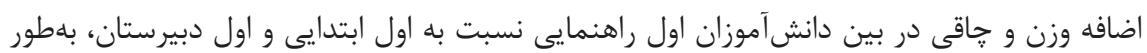

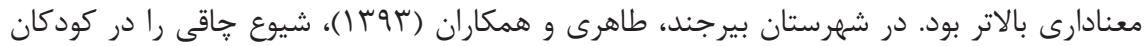

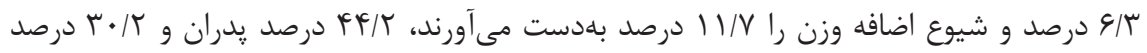

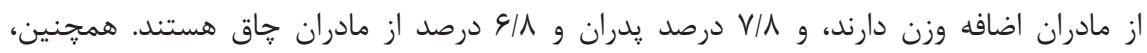
نتيجه مى گيرند كه ارتباط مثبت و معنادارى بين BMI فرزندان و BMI والدين وجود دارد. زاهدى و و مان

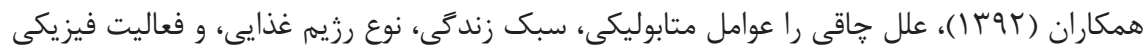
مى دانند كه مىتوانند تحت تاثير وراثت قرار كيرند.

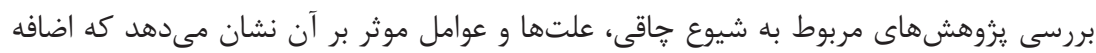
وزن بالا يك عامل شايع در كشور ايران در هردو جنس زن و مرد و در گروههاى سنى مختلف است.

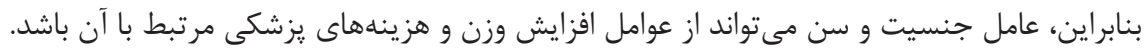

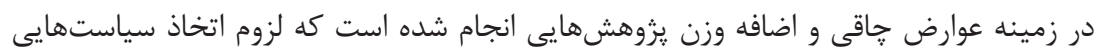

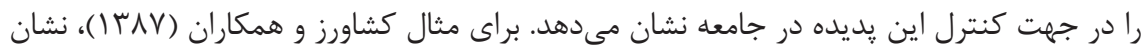

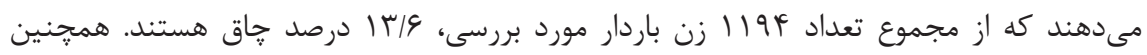

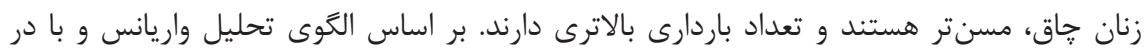

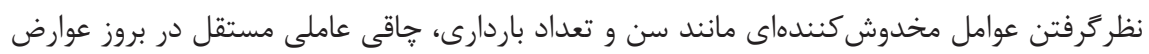


يرهـاكلاميسى'، فشار خون باردارى، و هيدرآمنيوس ' است. ميزان سزارين بهطور معنادارى در زنان

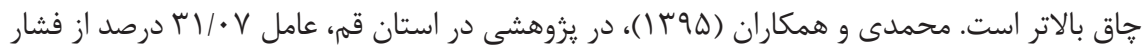

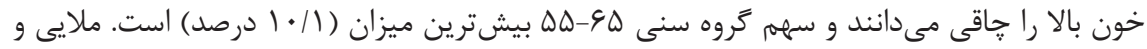

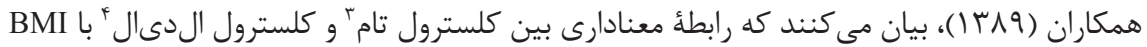

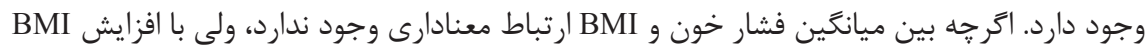
در ميزان فشار سيتوليكه و دياستوليك` نيز افزايش ديده مىشود. همانطور كه در اين يروهشها نشان داده مىشود، جاقى و اضافه وزن، عوارض زيادى بر سلامتى ايجاد مى كنند كه كنترل آن، علاوه بر ارتقاى سطح سلامتى جامعه، كاهش هزينههاى شخصى و اجتماعى را در يى ديى دارد.

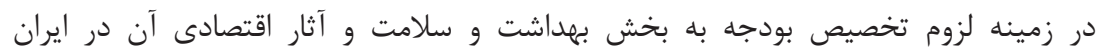
يزوهشهايى صورت كرفته است. جزايرى (IVVD)، بر لزوم داشتن برنامه اجرايى غذا و تغذيهاى با هدفهايى جون كاهش شيوع تغذيه بد در كودكان، بهبود كيفيت بهداشتى مواد غذايى، و تقويت

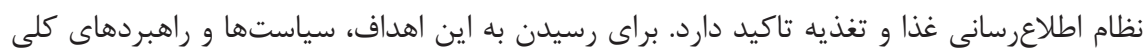

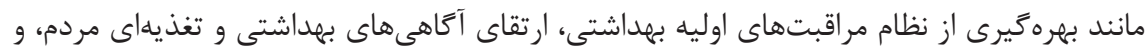

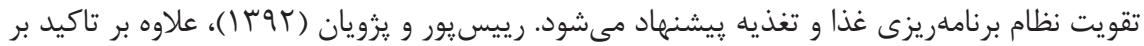

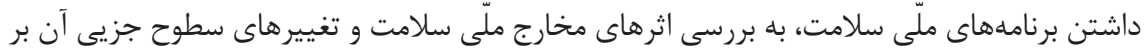

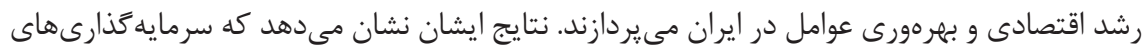

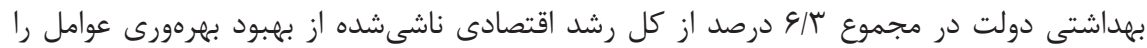

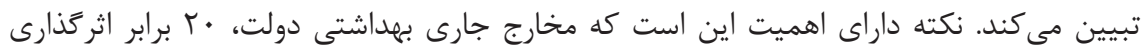
بيشترى در مقايسه با مخارج عمرانى بهداشتى دولت در دوره مورد يروهش دائ دارد.

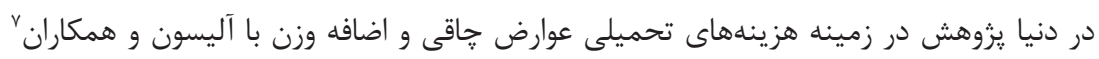

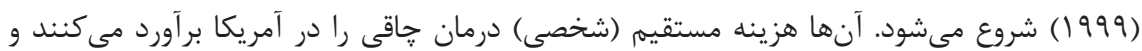

1. Pre-Eclampsia

2. Hydramnios

3. Total Cholesterol

4. LDL Cholesterol

5. Systolic Pressure

6. Diastolic Pressure

7. Allison et al 
سرانجام، شاخص خطر نسبى' را محاسبه مى كنند. در آن سال، برتون و همكاران' (999 (1)، هزينههاى سطوح مختلف شاخص توده بدنى را در جمعيت شاغلان (99.ب نفر) در شيكاگو محاسبه مى كنند.

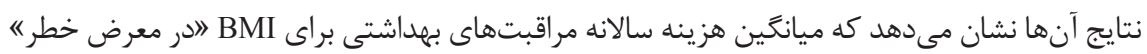

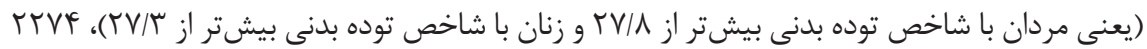

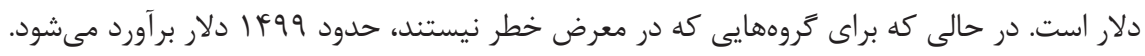

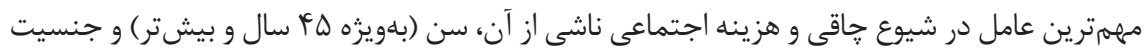

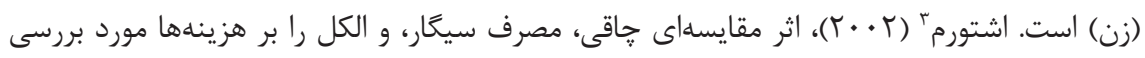

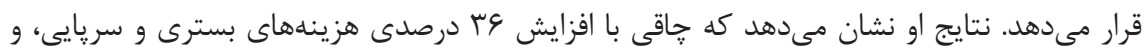
افزايش VV درصدى داروها در مقايسه با افزايش ال م درصدى هزينههاى بسترى و سريايى، و افزايش

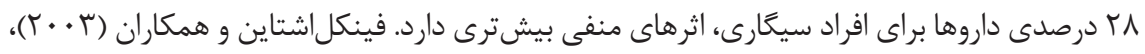

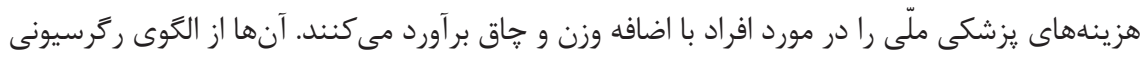

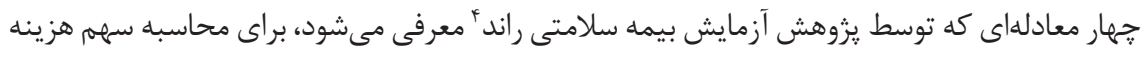

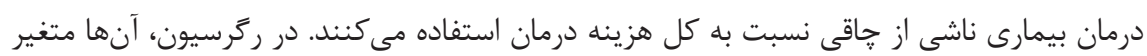
شاخص توده بدنى (به تفكيك دستابندىهاى مختلف)، متغير بيمه (به تفكيك نوع بيمه)، جنسيت،

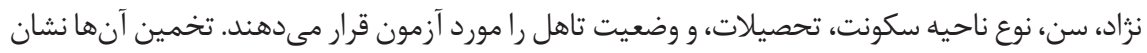

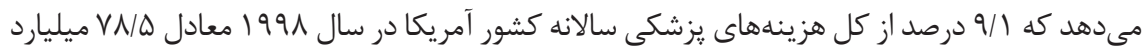

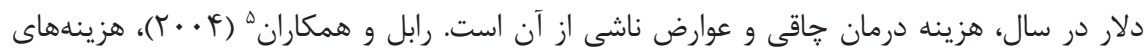
درمان يزشكى را براى دو گروه جاق و غيرجاق مورد بررسى قرار مى دهند. نتايجشان نشان مى مدهد كه

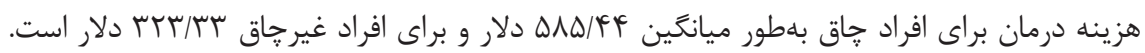

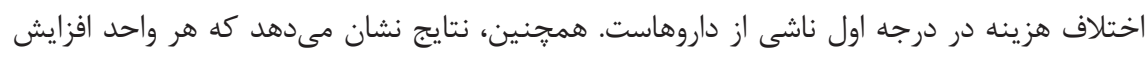

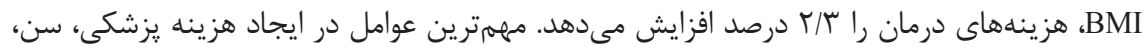

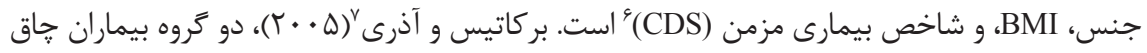

1. Relative Hazard Ratio-HR

2. Burton et al

3. Sturm

4. RAND Health Insurance Experiment

5. Raebel et al

6. Chronic Disease Score (CDS) Index

7. Bertakis \& Azari 
و غير جاق را از جهت هاى مختلف مقايسه مى كنند. نتايج نشان مىدهد كه بيماران جاق تعداد مراجعه بيشترى به مراكز مراقبتهاى ويزه و كلينيكهاى مراقبت ويزٔه دارند و داراى هزينه درمان بيشترى ماتى

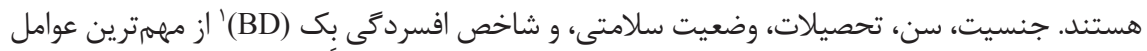

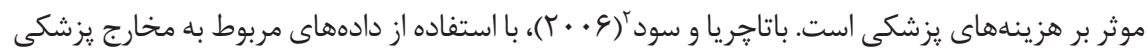

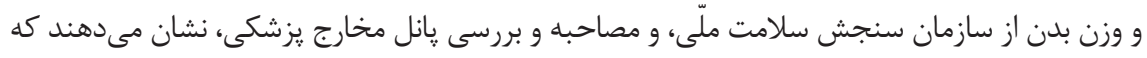

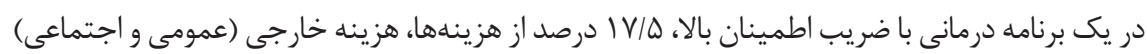

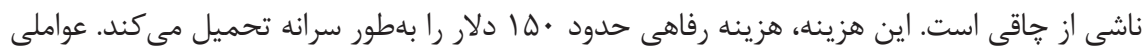

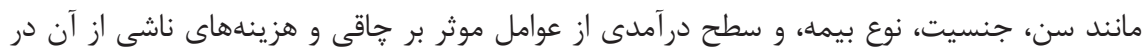

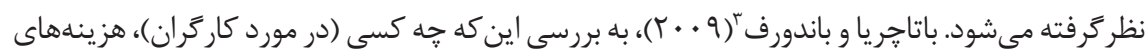

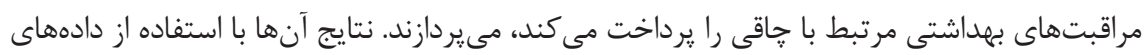

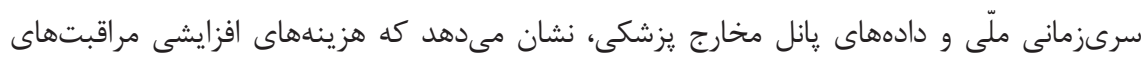

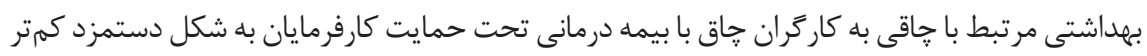

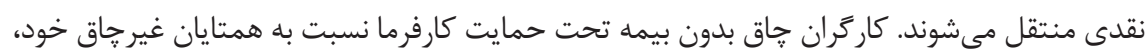

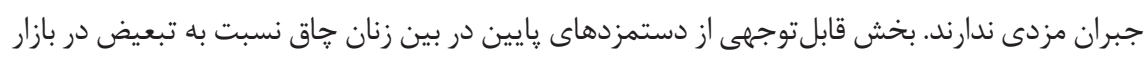

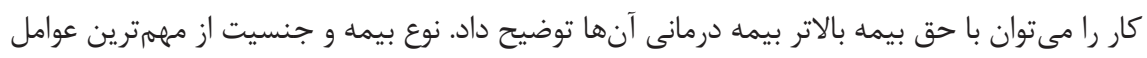

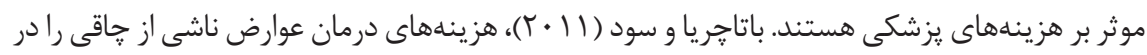
آمر يكا در جمعيتهاى مختلف زنان و مردان، و سياه و سفيد يوستان برآورد ميى كنند. عواملى مانى مانند سن،

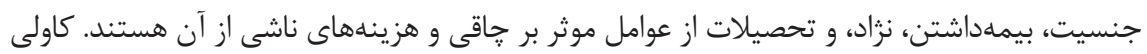

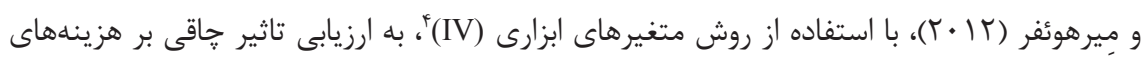

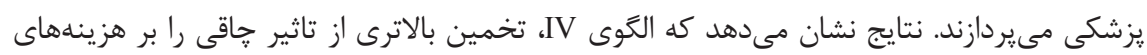

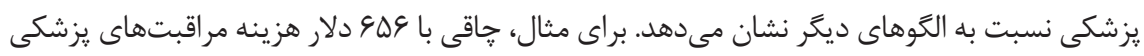

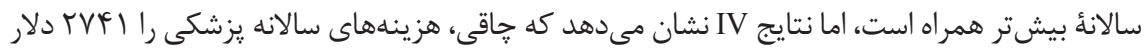

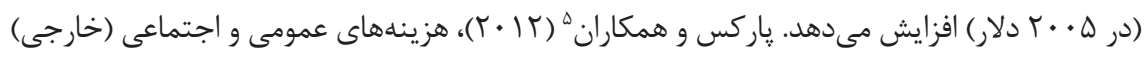
جاقى را در قالب مخارج مراقبتهاى بهداشتى با بودجه عمومى اندازمخيرى مى كنند. نتايج نشان مى دهدي

1. Beck Depression Index Scores

2. Bhattacharya \& Sood

3. Bhattacharya \& Bundorf

4. Instrumental Variable

5. Parks et al 
كه افزايش ا واحدى شاخص توده بدنى براى هر بزرَسال در آمريكا، هزينههاى سالانه يزشكى عمومى

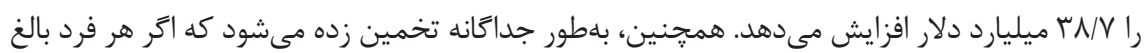

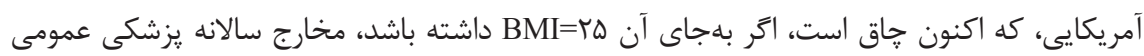

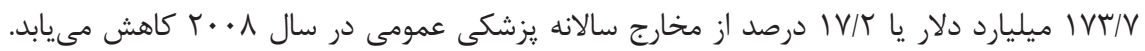
عواملى مانند سن، جنسيت، تحصيلات، سابقه بيمارى، سابقه مصرف سيعار، شاخص فقر (در آمد پإيين)،

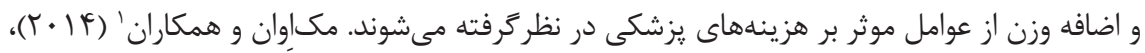

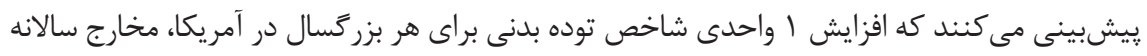

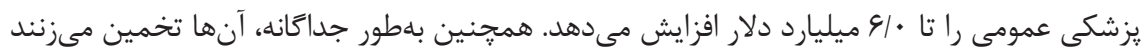

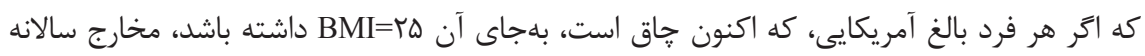

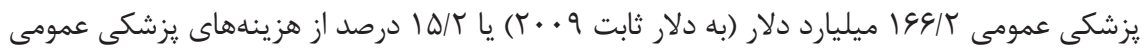

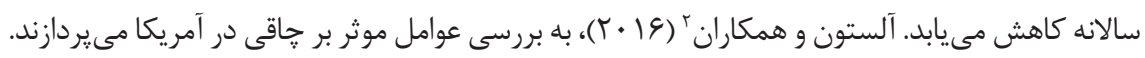

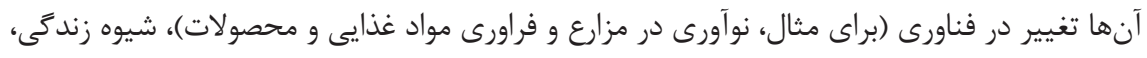

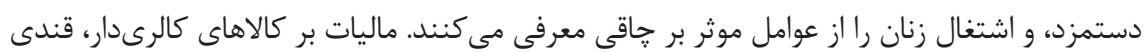
يا جرب، تبليغات تلويزيونى در جهت كاهش مصرف غذاهاى جرب، سياستهاى مربوط به برجّب زن مواد غذايى يا ساير برنامهاى آموزش تغذيه از راهكارهاى كاهش جاقى تعريف ميىشوند.

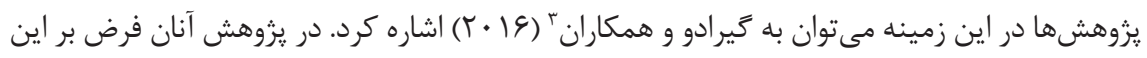

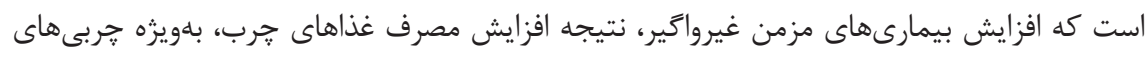

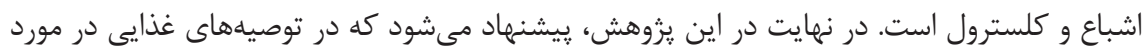

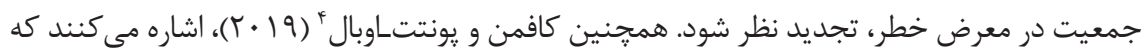

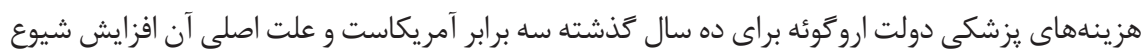

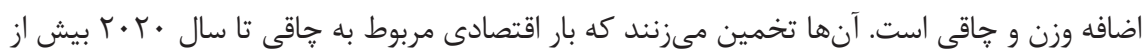
• • • ميليون دلار است كه رقمى نزديك به ا درصد از توليد ناخالص داخلى آن كشور است.

1. MacEwan et al

2. Alston et al 


\section{روش شناسى يزوهش}

\section{Sادها}

در اين يزوهش، براى برآورد الكوى اقتصادسنجى عوامل موثر بر هزينه يزشكى شخصى، از

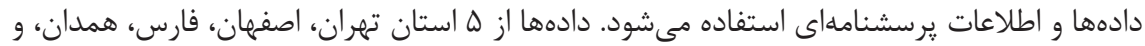

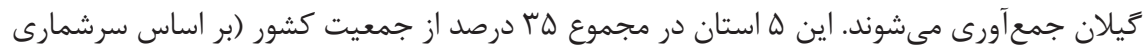

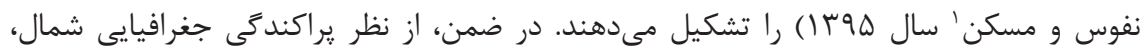

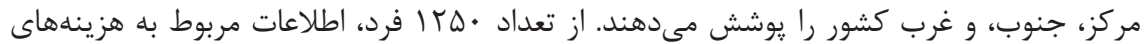
يزشكى شخصى و كلى ماهانه، درآمد ماهانه، سطح تحصيلات، نوع بيمه درمانى، وضعيت شغلى، ركي،

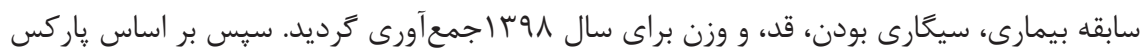

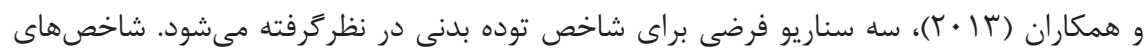

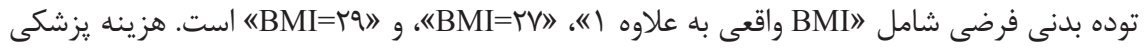

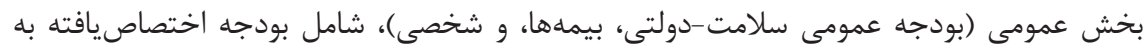

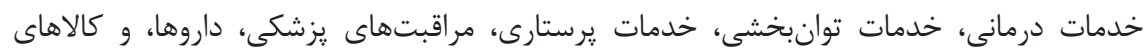
يزشكى اختصاصيافته به بيماران سريايى، خدمات بهداشت عمومى و پيشگيرى، مديريت سلامت،

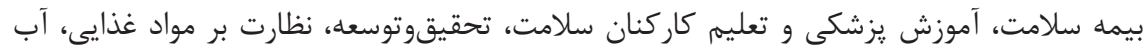
آشاميدنى و نكات بهداشتى، بهداشت محيط، و تشكيل سرمايه موسسههاى فراهمكننده خدمات سلامت در بيمارستانها، واحدهاى فراهمكننده خدمات ڤيرستارى و خدمات سريايى، داروخانهها، اداره سلامت عمومى، بيمه و تهيه كنندگان و ادارهكنندگان برنامههاى سلامت هستند كه براى

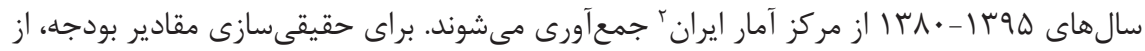

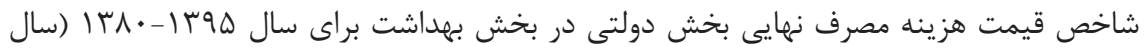

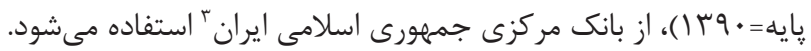

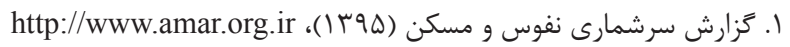

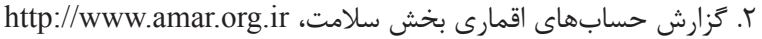

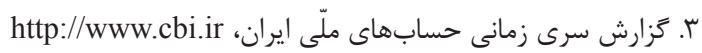


براى برآورد هزينه نهايى اجتماعى وجود اضافه وزن و رفاه ازدسترفته ناشى از آن در ايران

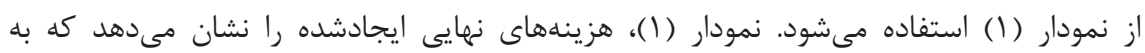
دليل وجود اضافه وزن، شامل هزينه نهايى شخصى (خصوصى-MPC)' و هزينه نهايى بخش عمومى

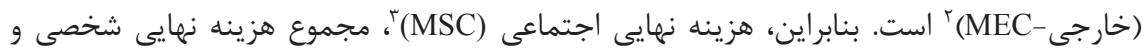

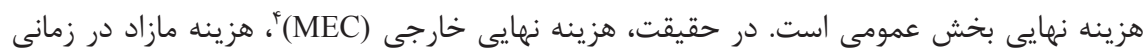
است كه بخش عمومى علاوه بر شخص (بخش خصوصى) انجام مىدهد. MSC اضافه وزن، تغييرهاى انتظارى در هزينه كل يزشكى (هزينه شخصى و عمومى)، به علاوه تغييرها در هزينه كل غيرمادى شخصى براى يك واحد افزايش در اضافه وزن در سطح مشخصى از اضافه وزن است. در اين تحليل،

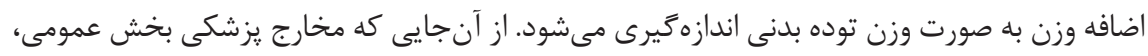

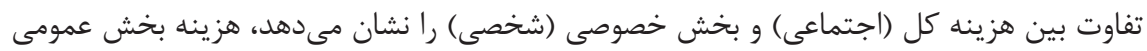
يزشكى مربوط به اضافه وزن مى تواند به صورت مقدار هزينه خارجى اضافه وزن محاسبه شود. اگر جه

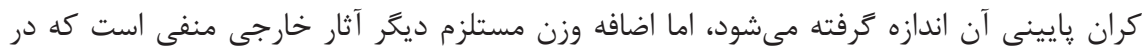

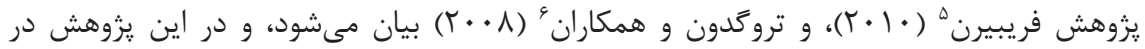

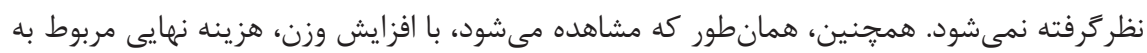

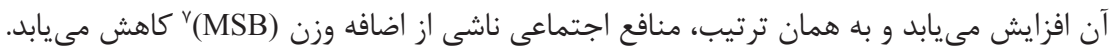

1. Marginal Private Cost

2. Marginal External Cost

3. Marginal Social Cost

4. Marginal External Cost

5. Freebairn 


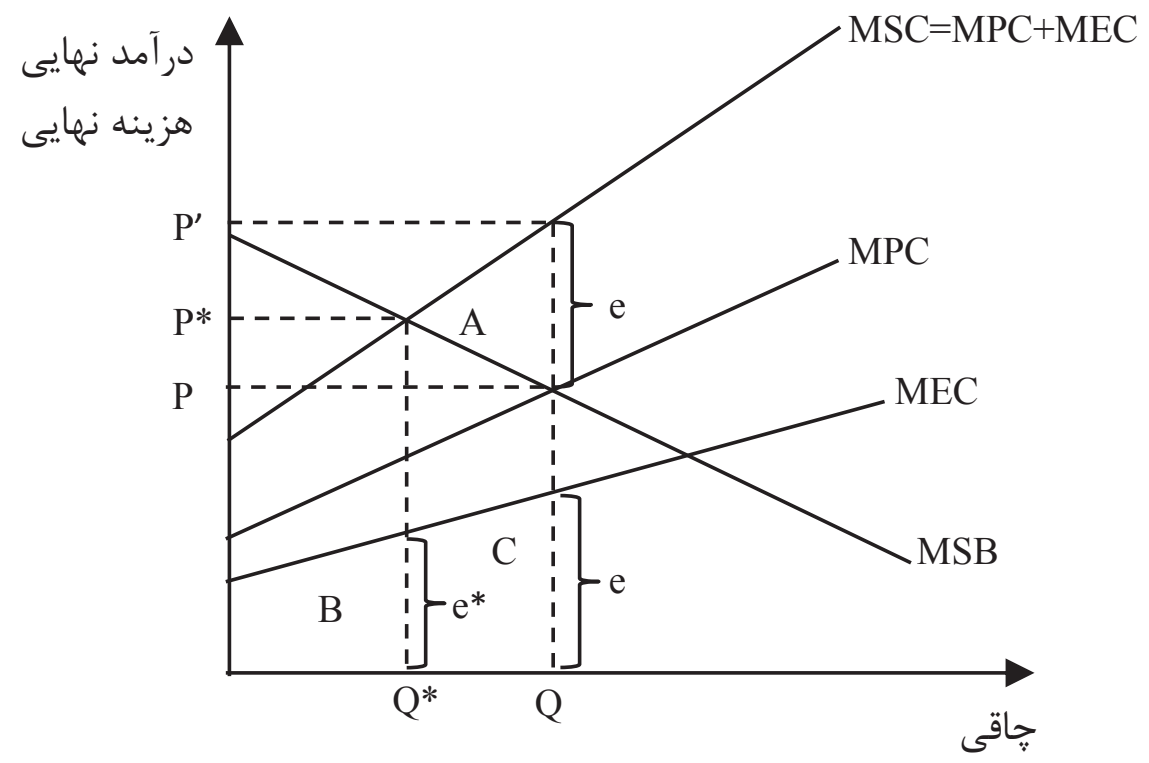

نمودار ا: هزينه نهايى خارجى اضافه وزن

تعادل هزينه نهايى اضافه وزن (شخصى، عمومى، و اجتماعى) بامنافع آن، سطوح بهينه شخصى، عمومى،

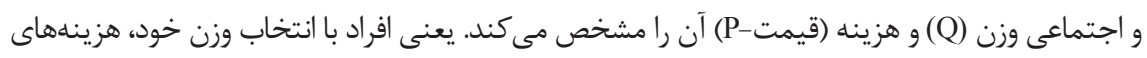

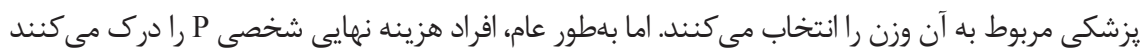

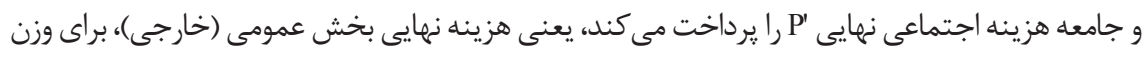

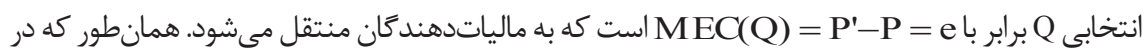

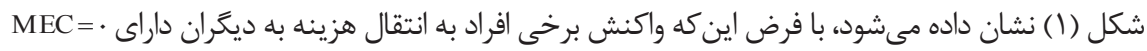

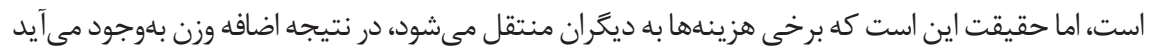

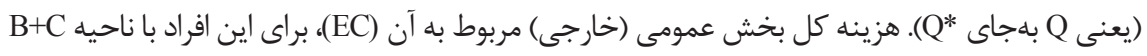

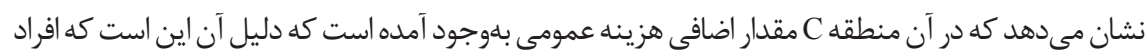

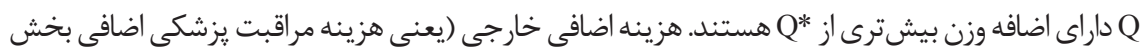
عمومى)، مىتواند به صورت رابطه ( ) اندازمخيرى شود: $\mathrm{C}=\mathrm{EC}(\mathrm{Q})-\mathrm{EC}\left(\mathrm{Q}^{*}\right) \approx \mathrm{e}\left(\mathrm{Q}-\mathrm{Q}^{*}\right)-\cdot / \mathrm{\Delta}\left(\mathrm{e}-\mathrm{e}^{*}\right)\left(\mathrm{Q}-\mathrm{Q}^{*}\right)$ 
كه در آن، * هزينه نهايى خارجى اجتماعى در وزن بهينه است. رفاه ازدسترفته (DWL)، مربوط به شيوع اضافه وزن Q به صورت ناحيه A است كه به صورت رابطه (r)

$$
\mathrm{A}=\mathrm{DWL} \approx \cdot / \Delta\left(\mathrm{P}-\mathrm{P}^{\prime}\right)\left(\mathrm{Q}-\mathrm{Q}^{*}\right)=\cdot / \Delta \mathrm{e}\left(\mathrm{Q}-\mathrm{Q}^{*}\right)
$$

همانطور كه در شكل (1) مشاهده مىشود، در سطح DWL نه نهايى براى افزايش اضافه وزن تقريباً برابر e است. هزينه كل (اجتماعى) خارجى اضافى مربوط به اضافه وزن، مجموع ناحيه C همه دهـ افراد و DWL كل مجموع ناحيه A همه افراد است. با توجه به شكل (1)، و روابط (1) و (Y)، مى (1) موان هزينه مازاد ايجادشده و رفاه ازدسترفته ناشى

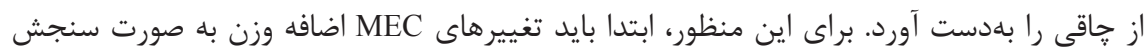

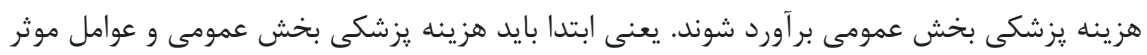

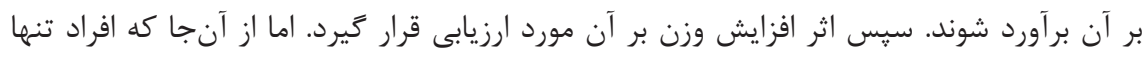

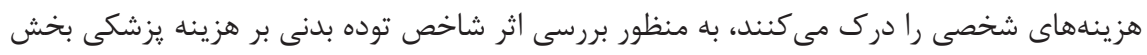
عمومى، از ركرسيون عوامل موثر بر هزينه شخصى استفاده مىشود. هزينههاى يزشكى شخصى شيى براى فرد iام (EC)

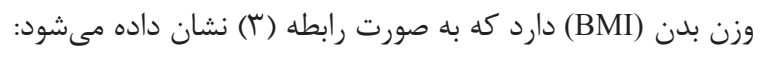

$\mathrm{EC}_{\mathrm{i}}=\mathrm{g}\left(\mathrm{BMI}_{\mathrm{i}}, \mathrm{X}_{\mathrm{i}}, \boldsymbol{\varepsilon}_{\mathrm{i}}\right)$

بنابراين، اثر نهايى يك واحد تغيير در وزن بدن بر هزينههاى يزشكى شخصى به صورت رابطه

فرمول در هم است.

براى افراد داراى اضافه وزن و افراد جاق مثبت است. يعنى انتظار معرود كه هزينه نهايى هر واحد اضافى وزن بدن با افزايش وزن بدن افزايش يابد و اين اثر مىتواند با تغيير در مقدار ديگر

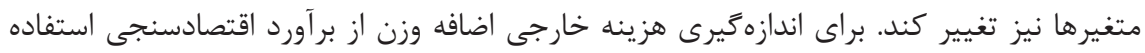
مىشود. هر اندازهاى مستلزم مقايسه هزينه بين وضعيت واقعى فعلى و وضعيت جايكزين (بديل) 


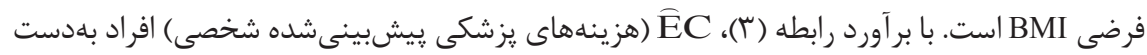

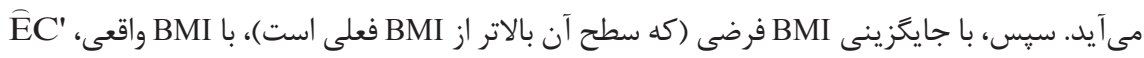

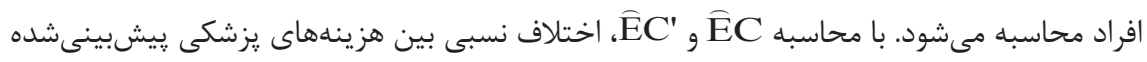
شخصى با BMI واقعى و يیشبينىشده با سناريوهاى فرضى براى افراد جامعه محاسبه مىشود. $\% \Delta \widehat{\mathrm{EC}}=\frac{\left(\widehat{\mathrm{E} C}-\widehat{\mathrm{E}} \mathrm{C}^{\prime}\right)}{\widehat{\mathrm{EC}}}$

رابطه (ه)، بيانكر آن است كه اگر بهجاى BMI فعلى، BMI بالاترى (فرضى) قرار كيرد، هزينه

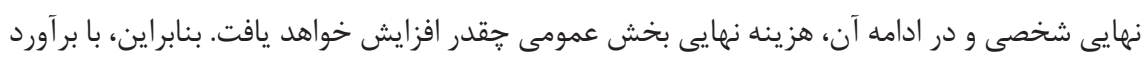
درصد افزايش هزينه نهايى ناشى اضافه وزن (افزايش شاخص توده بدنى)، تغييرهاى هزينه اجتماعى نهى (كل) سالانه ناشى از اضافه وزن در كشور (PME

هزينه يزشكى كل يرداختشده (شخصى و بخش عمومى)، در سال در كشور است. براى PME

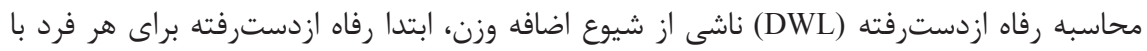

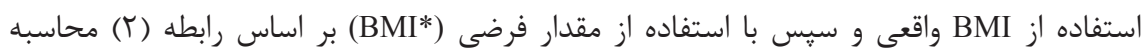

با توجه به رابطه (V)، نرخ (نسبت) DWL نسبت به هزينه يزشكى شخصى در شرايط سناريوى

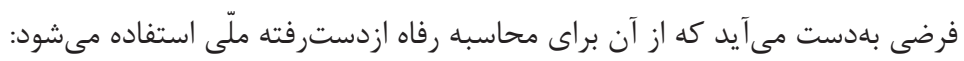
$\% \mathrm{DW} L=\frac{\mathrm{DW} L}{\widehat{E} \mathrm{C}}$

با توجه به محاسبه نسبت رفاه ازدسترفته نسبت به هزينه يزشكى شخصى، بر اساس هزينههاى

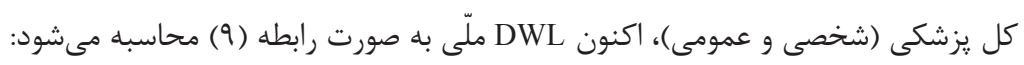
$\mathrm{NDEL}=\% \mathrm{DW} \mathrm{W} \times \mathrm{PME}$ 
بنابر اين در اين يزوهش، ابتدا بر اساس رابطه (بّ)، الكوى اقتصادسنجى عوامل موثر بر هزينه يزشكى

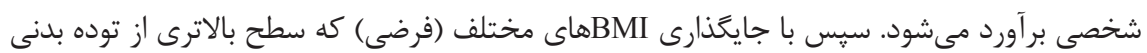

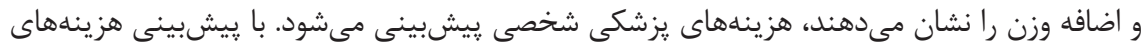
يزشكى شخصى، درصد افزايش اين هزينهها بهدست مى آيد (رابطه Q). با استفاده از اين درصد، افزايش هزينههاى اجتماعى (شخصى و عمومى)، ناشى از اضافه وزن بهدست مى آيد (رابطه ؟). همجنين، با برآورد اثر شاخص توده بدنى بر هزينه يزشكى شخصى (رابطه عا)، رفاه ازدسترفته ناشى از اضافه وزن

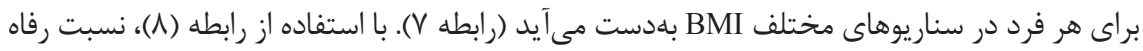
ازدسترفته به هزينه يزشكى شخصى و رفاه ازدسترفته ناشى از اضافه وزن (رابطه 9) محاسبه ميىشود.

\section{نتايج يزوهش}

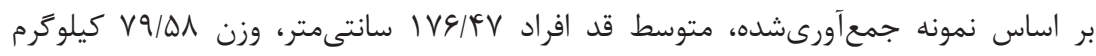

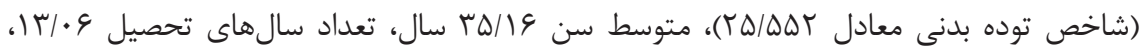

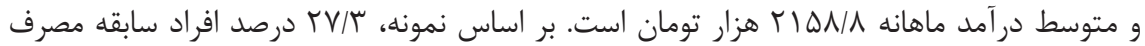

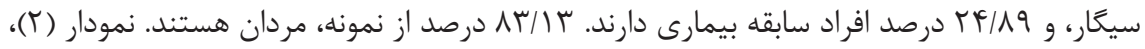
وضعيت شغلى و نوع بيمه درمانى افراد را نشان مى دهد.
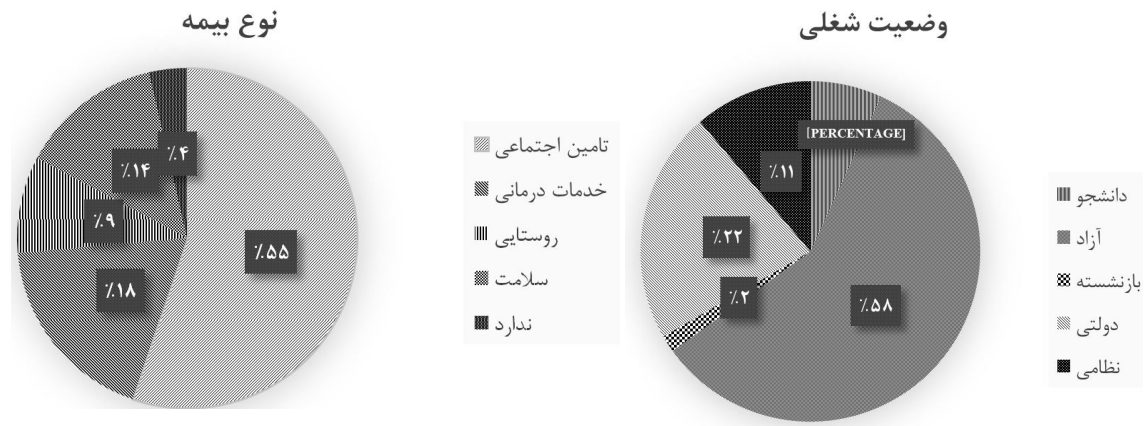

نمودار r: وضعيت شغلى و بيمه نمونه

با جمع بودجه خدمات درمانى، خدمات توانبخشى، خدمات يرستارى، و مراقبتهاى يزشكى، داروها

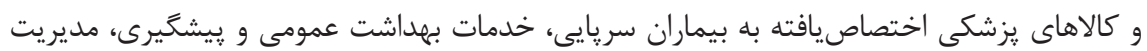


سلامت، و بيمه سلامت، هزينههاى جارى سلامت (يزشكى) بهدست مىآيد. با جمع هزينههاى جارى سلامت با تشكيل سرمايه موسسههاى فراهمكننده خدمات سلامت، كل هزينههاى سلامت بهدست

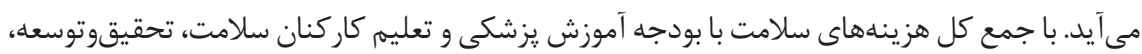

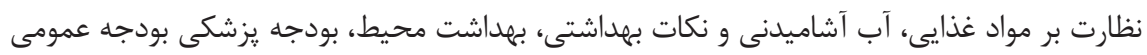

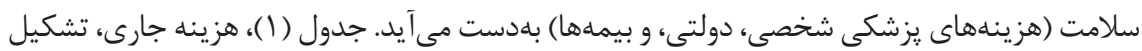

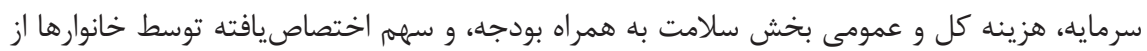

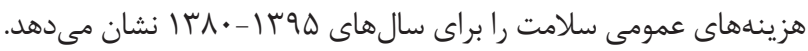

جدول 1: هزينه جارى، تشكيل سرمايه، هزينه كل و عمومى بخش سلامت بله به همر اه بودجه، و سهم

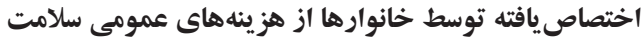

\begin{tabular}{|c|c|c|c|c|c|c|}
\hline خانوارها & بودجه خانوار & بودجه عمومى & كل هزينه & سرمايه & هزينه جارى & سال \\
\hline$\Delta r / \varepsilon \mid$ & rTq1FEVI & FrAVTrVq & F. rqvqkr & $I D F V \cdot T \cdot$ & rAVQ. qrr & $1 r \Lambda$. \\
\hline$\Delta \cdot / \Delta \varphi$ & rGQVF-Ar & QTHQITQV & $\Delta \cdot r \cdot 91 \Delta r$ & IDE.rTA & 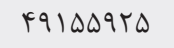 & $|r \lambda|$ \\
\hline $\mathrm{FV} / \cdot \mathrm{\Lambda}$ & MI. GNFE. & 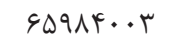 & GTTYRTAT & ITVTTMV & $9 \cdot 1 \Delta \Delta \cdot 19$ & irat \\
\hline$\Delta T / Q G$ & FVqFaV.r & $9 \cdot \Delta r F T I q$ & $\Lambda \varepsilon \Delta \Delta \wedge \vee \cdot \uparrow$ & I QVAIOT & $\Lambda F \Delta \Lambda \cdot \Delta \Delta T$ & Ir人 \\
\hline$\Delta r / \varnothing q$ & GI FEOVTD & $11994 \Delta \cdot 4 q$ & $111 V \times r \Delta 19$ & $r F \cdot \Delta r g F$ & $1 . q r r \Lambda \cdot \Delta \Delta$ & IrAF \\
\hline$F V / r q$ & $9999 \wedge \Lambda \Delta 9$ & $|F| \& \& V E \& 4$ & $I T Y \wedge \Delta \Lambda \mid E V$ & 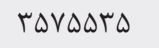 & ITAYATETT & IrNa \\
\hline FN/qT & AVVEINFT & IVATrTrTa & IVETVqFIT & gqvrequ & $1994 \cdot \Delta 9 Y$. & Ir人s \\
\hline $0 \cdot / 9 f$ & llFrqIVqF & THFTDQTHE & TY. QGTVGV & VATrIFV & rIr.rQGr. & IrAv \\
\hline$\Delta T / \Delta F$ & $1 \Delta \cdot F \psi \Delta \cdot+4$ & TAGTTVVII & $r(19109 \Delta F$ & $\wedge r \wedge \cdot q \hookrightarrow \Delta$ & rVrrmfq19 & IrNA \\
\hline$\Delta V / F q$ & $r \cdot g \Delta F \| \ldots$ & 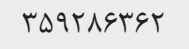 & rIFIrIQA. & V.FTrTd & $r \cdot v \cdot \Lambda \Lambda r \Delta \Delta$ & $1 r \wedge 9$ \\
\hline $9 \cdot / 199$ & TYYDAI-NT & FarVqTIGG & FIV. qRTD & 11199948 & $F r \cdot \Delta \cdot 9 V \wedge q$ & $14 q$. \\
\hline$\Delta T / \Lambda \Delta$ & TV..IVDII & DI. AVTFYq & FADTGG.91 & 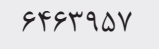 & $F \vee \Lambda \Lambda \cdot r|f|$ & $\mid r q 1$ \\
\hline$F \Delta / \Delta K$ & 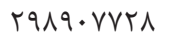 & 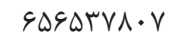 & GTISTMTAK & IIfIVEV. & $G 1 \cdot r \cdot \Delta \Lambda 1 r$ & Irar \\
\hline$r N / \Delta \Delta$ & 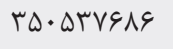 & १.१५१९१५Ь & $\Lambda \& F G \cdot r \cdot r t$ & 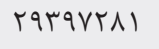 & $\Lambda r \Delta r \cdot G V \Delta I$ & ז \\
\hline $\mathrm{rV} / \cdot \Lambda$ & F.. 9q94ro & $1 \cdot \Lambda \cdot \vee \backslash \vee \backslash 1 \cdot$ & 1. rENFGVDG & TrTQQ1Q1 & $1.1 F \Delta \Lambda V G \cdot \Delta$ & 1494 \\
\hline TH/FG & fiv...IVVI & $15 \cdot 9999.19$ & IVQTFDDGTY & rNIQIr.. & IITKF. FHT & $1 \pi 90$ \\
\hline
\end{tabular}


با توجه به دادها و اطلاعات جمعآورىشده از ه استان تهران، اصفهان، فارس، همدان، و كيلان،

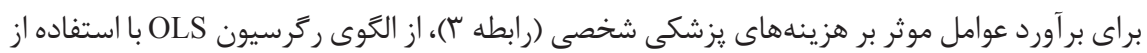

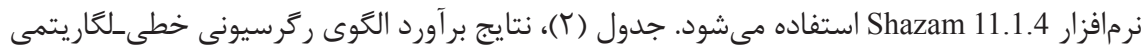
را نشان مىدهد. به منظور بررسى معنادارى ضرايب، از آماره t استفاده مىشود. همجنين، آزمون

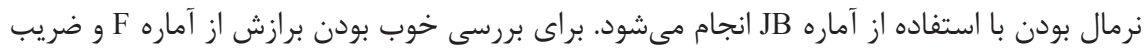

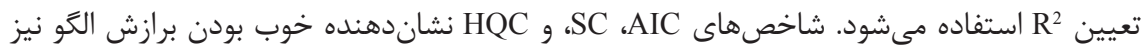
هستند. آماره دوربين واتسون براى بررسى نبود خودهمبستگى برآورد مىشود. همجنين، آزمون

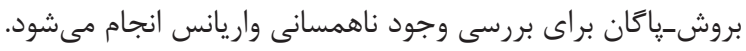

جدول r: برآورد الكوى هزينههاى يزشكى شخصى در ايران (رابطه r)

\begin{tabular}{|c|c|c|c|c|c|c|}
\hline كشش & I ضمبستخى & P-Value & آماره t & خطاى استاندارد & ضريب & متغير \\
\hline$\cdot / \Lambda \cdot \Lambda$ & $\cdot|\cdot|+\mid$ & $\cdot / \cdot \Delta r \Lambda$ & G/T & r/VA & $|r /| F$ & لحًاريتم شاخص توده بدنى \\
\hline \multirow[t]{2}{*}{$r / 991$} & $\cdot / r \cdot r$ & $\cdot 1 \cdot \cdot 1$ & $r / r \mu$ & $|r /| F$ & $r q / r \Delta$ & لكاريتمم سن \\
\hline & $\cdot /$ TVG & $\cdot 1 \cdot$ & $9|\pi|$ & N/FF & $\Delta T / T F$ & متغير موهومى زنان \\
\hline \multirow[t]{3}{*}{$\cdot \mid \Lambda \Delta V$} & . /NAr & $\cdot 1 \cdot r$ & r/^ & $9 / 19$ & $|V| A \mid$ & لكار يتم تعدادسال هاى تحصيل \\
\hline & $\cdot / \pi 9 \Delta$ & $\cdot 1 \cdot$ & 9191 & $V|\varphi|$ & $\Delta \cdot 119$ & متغير موهومى سابقهبيمارى \\
\hline &.$/ \cdot 1 \mathrm{f}$ & . IATH & $\cdot \pi t$ & $V / \cdot r$ & $1 / \Delta V$ & متغير موهومى مصرف سيكار \\
\hline \multirow[t]{3}{*}{$\cdot 1 \cdot 11$} & .1 .94 & - /IQT & $1 / 4 r$ & $N / T F$ & $11 / \wedge \Delta$ & لكًاريتم شاخص فقر \\
\hline & $-\cdot / 10$ & $\cdot 1 \cdot 1 \mathrm{f}$ & $-Y / F V$ & $V \wedge / \cdot \Delta$ & $-19 \% / \cdot r$ & ثابت \\
\hline & $\begin{array}{c}\mathrm{F}=r V / \leftarrow V \\
\mathrm{AIC}=r q \Delta / \Delta\end{array}$ & & $\begin{array}{l}\mathrm{R}_{2}= \\
\mathrm{SC}=\end{array}$ & $\begin{array}{l}\text { - } 1 \text { А१९१ } \\
\text { FFY/AD }\end{array}$ & $\begin{array}{c}\mathrm{DW}=1 / 9 \varepsilon \\
\mathrm{HQC}=q \mid r / q \varepsilon\end{array}$ & $J B=\cdot / 4 r \& q$ \\
\hline
\end{tabular}

همانطور كه در الكَى عوامل موثر بر هزينههاى يزشكى شخصى مشاهده مىشود، اثر شاخص

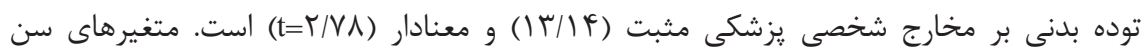

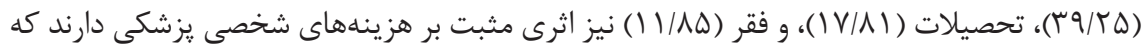
در اين ميان، شاخص فقر اثر معنادارى ندارد (t=1/Fr). در اين :يزوهش، شاخص فقر، نسبت درآمد

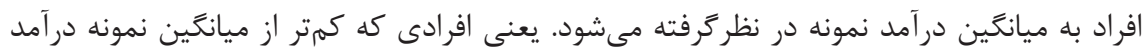


دارند، در دسته افراد زير خط فقر در نظركرفته مىشوند. همانطور كه مشاهده مىشود، كمبود درآمد،

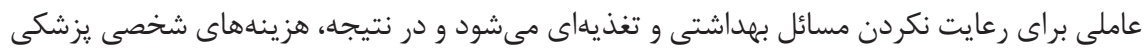
را افزايش مى دهد. داشتن سابقه بيمارى اثرى مثبت (A

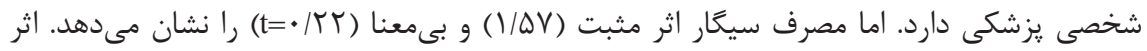

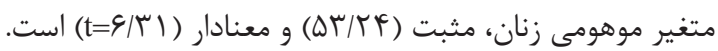

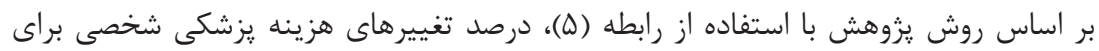

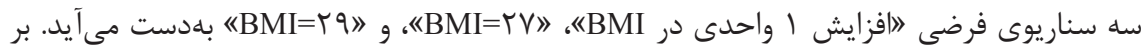

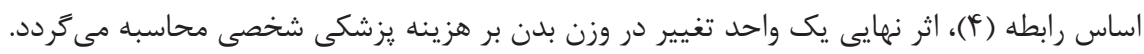

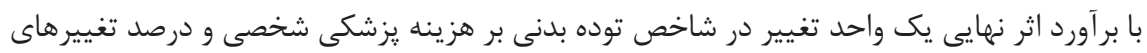

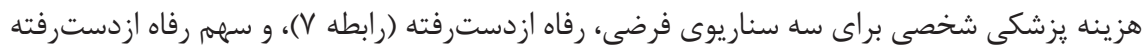

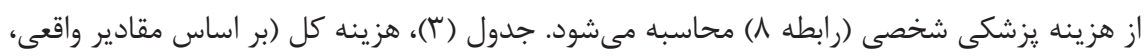

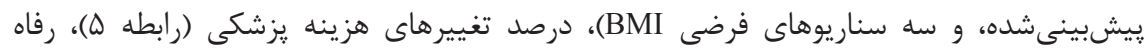
ازدسترفته (رابطه V)، و سههم رفاه ازدسترفته از هزينه يزشكى شخصى (رابطه ()) را نشان مي دهد.

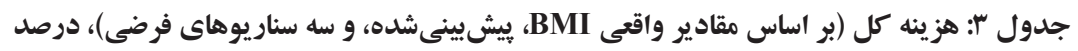

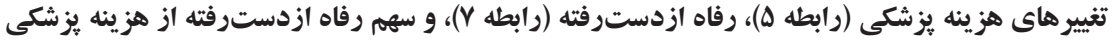

عمومى (رابطه ( )

\begin{tabular}{|c|c|c|c|c|c|}
\hline DWL/EC & $\begin{array}{c}\text { DWL } \\
\text { (ماهانه_هزار تومان) }\end{array}$ & $\%$ EC & هزينه يزشكى شخصــــار تومان) & سناريو & BMI \\
\hline & & & $\Delta 1 / \cdot r \Delta$ & $r \Delta / \Delta \Delta T$ & واقعى \\
\hline & & & $\Delta 1 / T \cdot q$ & $r \Delta / \Delta \Delta T$ & ييشبينى \\
\hline.$/ 1 T \Lambda$ & G|DS & T/KI & $\Delta T / K q T$ & TE/DQT & سناريو 1 \\
\hline$\cdot / 1 \wedge \varphi$ & $9 / \Delta 1$ & $r / v q$ & $\Delta r / l F \lambda$ & TV & سناريو r \\
\hline - MFT & Tr/G & D/GT & $\Delta F / \cdot \Lambda V$ & rq & سناريو r \\
\hline
\end{tabular}

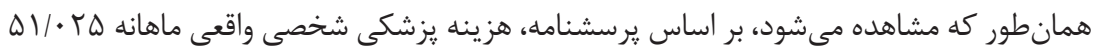

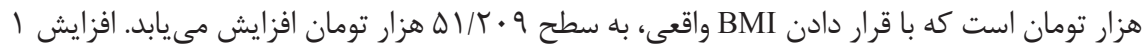

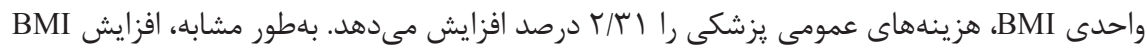




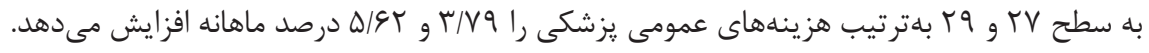

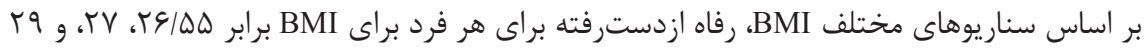

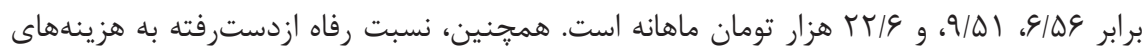

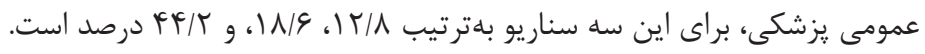

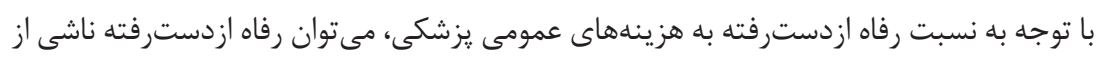

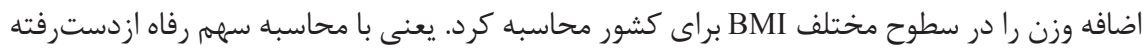

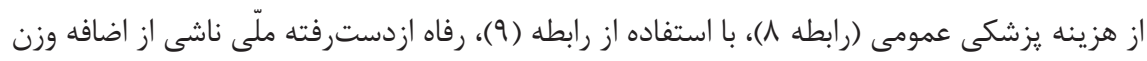

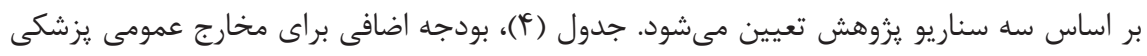
ناشى از افزايش BMI، به سه سطح rهD

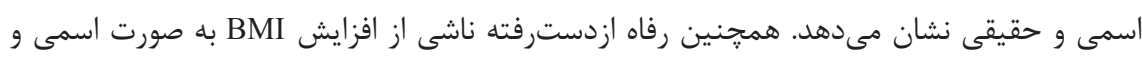
حقيقى نشان داده مىشود. همانطور كه مشاهده مىشود، افزايش ا واحدى در شاخص توده بدنى، بودجه اضافى بخش مدرد

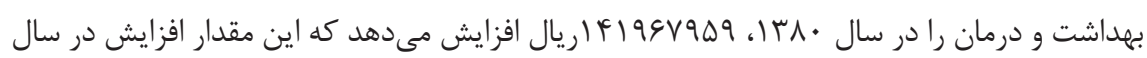

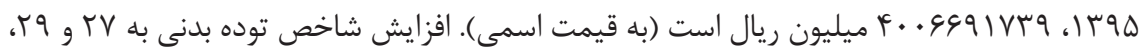

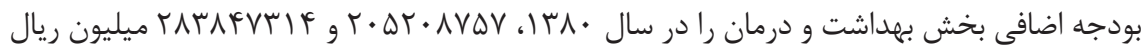

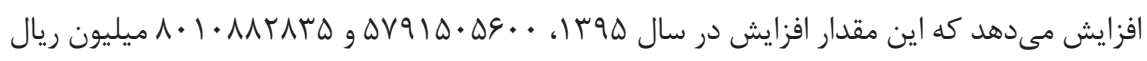
خواهد بود (به قيمت اسمى). بر اساس اين مقادير بودجه اضافى، رفاه ازدسترفته ناشى از اضافه وزن

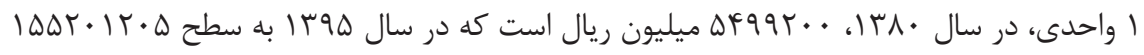
ميليون ريال مىرسد (به قيمت اسمى). افزايش شاخص توده بدنى به VY و و ؟، رفاه ازدسترفتهاى

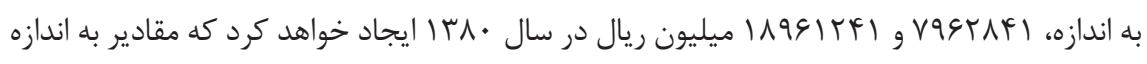

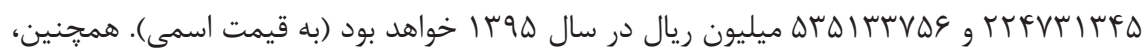
افزايش ا واحدى شاخص توده بدنى در بودجه اضافى بخش بهداشت و درمان در سال •^rا (به قيمت حقيقى)، نوساندار است. اين مسئله براى افزايش شاخص توده بدنى به ل Y و و و ن نيز است.

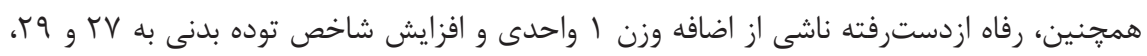
همراه با نوسان است. 
جدول †: بر آورد هزينه فرصت ازدسترفته ناشى از اضافه وزن در ايران (اسمى و حقيقى ـ بر اساس سه

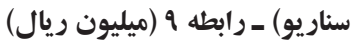

\begin{tabular}{|c|c|c|c|c|c|c|}
\hline \multicolumn{3}{|c|}{ رفاه ازدسترفته } & \multicolumn{3}{|c|}{ افزايش بودجه } & \multirow{2}{*}{ سال - - } \\
\hline$B M I=r q$ & $\mathbf{B M I}=r V$ & $\mathbf{B M I}=r q / \Delta \Delta r$ & $B M I=r q$ & $\mathbf{B M I}=r V$ & $\mathbf{B M I}=r q / \Delta \Delta r$ & \\
\hline & & & اسمى & & & \\
\hline$|199|$ TYI & VAGTAFI & DFqqT.. & TAKNFVTIF & $r \cdot \Delta T \cdot \wedge V \Delta V$ & $14199 V 909$ & $\| \mu \wedge$. \\
\hline 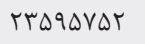 & $99.91 \% 1$ & SAFTIE & TAKTTOHKQ & 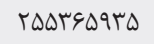 & 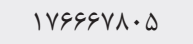 & $|r \wedge|$ \\
\hline 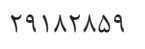 & ITTDDFFE & AF\&rV.G & 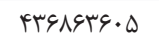 & rIDArTE.人 & rIAFq991V & IrAT \\
\hline$p \cdot r \cdot v \varepsilon q$ & IEN|QTED & IISITVAT & $\Delta 994 \cdot \Delta 119$ & FTMTETVI & 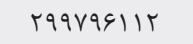 & IrNK \\
\hline$\Delta \backslash \Delta \wedge \wedge \Lambda \cdot V$ & risq4q. D & $|f 98| 901$ & RVTTVVYTq & DQNKTINF. & 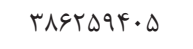 & Ir人F \\
\hline 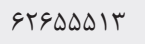 & TETITY.A & INIVIDQT & 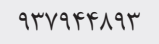 & $9 V 1.91997$ & 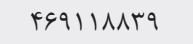 & $\| \pi \wedge \Delta$ \\
\hline varirgis & & 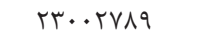 & IAVTIFATV & $\Lambda \Delta \wedge r \vee \& \& \Delta \Delta$ & DQTNFTDAT & Ir人s \\
\hline 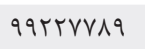 & $F|\& V| \cdot 9 V$ & rAVVArGI & IFADFTVII9 & 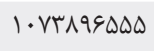 & VFTqRDF. T & IrیV \\
\hline ITGGKYGD. & $\Delta r \mid \Lambda \cdot G V V$ & rGVTGqAV & IN9QV.FTGV & $\| r V \cdot \Delta \cdot \Lambda r \Delta \Lambda$ & $9+\wedge \mid f \wedge \cdot 11$ & 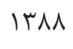 \\
\hline $1019 \cdot r 191$ & GQVTIDQ. & $F G \cdot \Lambda \Delta K T F$ & TrVAVFATVA & IVIGVTDITV & 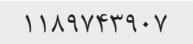 & $1 \% \wedge 9$ \\
\hline$r \cdot r \Delta V q \mid r$ & $\wedge f \cdot q \wedge q \cdot \Delta$ & $\Delta \Lambda \cdot V q r \Delta F$ & rqqVAr. FVr & 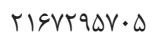 & 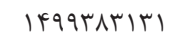 & 1\%q. \\
\hline TRDGFEFT & 9FAMEIVE & GDQTQITV & 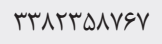 & TEFATGTTAT & $1991 \mathrm{~V} \cdot V Y 9 \Delta$ & $|r q|$ \\
\hline$r q \cdot r \varepsilon \wedge l \cdot V$ & ITIGFI|rI & NFTITYAN & FTYGVVTADV & TIfrDI99VE & rIVF.GFへGr & \\
\hline$F \cdot r r \cdots \Delta F q$ & $19 \wedge 9 \cdot \Delta \Delta \& V$ & 11 sqfVEq1 & $q \cdot r \cdot \wedge \wedge 999 \uparrow$ & FTUTAT.AVT & r. IITAFVTF & س \\
\hline qrVqV.qqq & $r \cdot V r \Delta F q r$ & ITAGTYOVA & $\vee \backslash \Delta \Delta|\Delta \wedge \Delta \Delta|$ & $\Delta I V T \wedge \Delta D G \wedge \Delta$ & $r \Delta \vee \wedge ६ ৭ ૬ \cdot r \vee$ & Irqf \\
\hline DTDITIVDS & THFVTITHE & $1 \Delta \Delta T \cdot \mid T \cdot \Delta$ & $\Lambda \cdot 1 \cdot \Lambda \Lambda T \wedge r \Delta$ & $\Delta \vee q \mid \Delta \cdot \Delta \varepsilon .$. & f.. c૬qq।Vrq & $1 \pi q \Delta$ \\
\hline
\end{tabular}


ادامه جدول †ا: بر آورد هزينه فرصت ازدسترفته ناشى از اضافه وزن در ايران

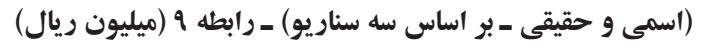

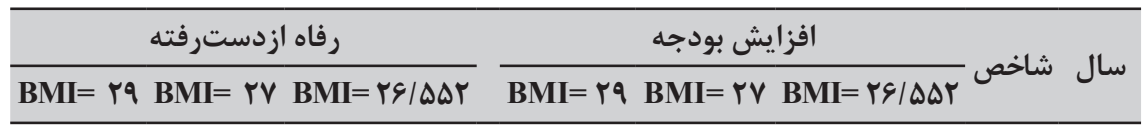

\begin{tabular}{|c|c|c|c|c|c|c|c|}
\hline 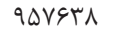 & $Y \cdot r \mid g \varphi^{F}$ & TVVVTr & IFTrDVYT & $1 . r g q \cdot V q$ & VIV..99 & $19 / 1$ & $1 \pi \Lambda$. \\
\hline $1 \cdot r \Delta q \cdot r$ & $k r \cdot \wedge r \mid$ & rqvara & lQTUVGTF & III. TAYV & VGNIT.q & rr & $|r \wedge|$ \\
\hline $1 \cdot 1191 \%$ & FoVTqY & $r|\Delta \Lambda|$. & $|\varepsilon r \cdot \cdots \Lambda|$ & IIVAFrqq & 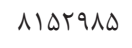 & re/A & IrAT \\
\hline ITVIITE & DrrAIA & 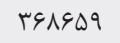 & 19. rAVrF & $\| r v \Delta \varphi q \mid r$ & QDIVTrV & TI/Q & IrAT \\
\hline IFIVTVD & $\Delta 9019$. & $411 \cdot k r$ & TITIEFTI & IDTHADIT & $1.911 \Delta T K$ & $r G / F$ & IrAF \\
\hline $10 \cdot 98 V 1$ & GMF. MF & crvıcq & TrG.1.人r & 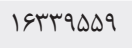 & $\| r \cdot 4 \cdot q \Lambda$ & $f 1 / 0$ & IrNa \\
\hline IGTOHTY & GNGVGF & FVETAF & TFYA.VIT & IVGQAFFV & ITTFEIVY & $F N / D$ & IrNG \\
\hline $19 \Delta 9 \Delta \Delta V$ & $99 \Delta 9 \mathrm{VV}$ & $F \lambda . F F$. & FFVqAFFq & IVATAIDG & $1 T F \cdot r \cdot 9 \Delta$ & $\Delta 9 / 9$ & IrAv \\
\hline IVVADVV & V\&\&9T. & $\Delta I \Delta \Lambda Y \Lambda$ & TGGTD.G. & IOTFAVIT & פוד & $V I / r$ & IrNA \\
\hline 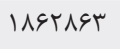 & VArtis & $\Delta F \cdot T V T$ & TVAMENIF & $r \cdot 19 \cdot 9 \cdot r$ & Irqfrve. & $\Lambda \Delta / \Gamma$ & $1 \% \wedge 9$ \\
\hline r..rAVG & 14.919 & $\Delta \Lambda \cdot V q F$ & 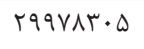 & TI\&VTQDV & 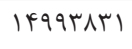 & $1 \ldots$ & 149. \\
\hline $11119 \cdot f$ & 19.919 & DTDFqF & rVIrrqצג & $199 \cdot 94 \cdot 1$ & IrDGGTIV & $1 T \Delta$ & 1491 \\
\hline IENTHIA & $V \cdot 9499$ & FAvqII & $r \Delta I \wedge F \cdot \wedge F$ & INT.99DT & $1 T \Delta q \Delta q V K$ & IVT & Irar \\
\hline IVGqFV. & VAT. 9D & DITIAV & KEYAAVTV & $1910 \cdot 101$ & IKTYAD.r & TrV & rצו \\
\hline $199 \wedge \Delta F \Delta$ & VIrri. & FqYG|N & TQFTV..r & INTNTOVT & ITVIVEV. & TAl & 1494 \\
\hline IErq.rr & gNFIIf & FVTFAF & TFTAGTFq & $|V G F \cdot| D F$ & $|r| 999 \pi \mid$ & rTq & 1490 \\
\hline
\end{tabular}

بحث و نتيجه

هدف اين يزوهش، بررسى اثر ميزان اضافه وزن و جاقى بر هزينههاى شخصى يزشكى در ايران،

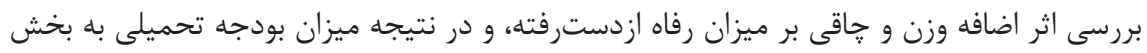

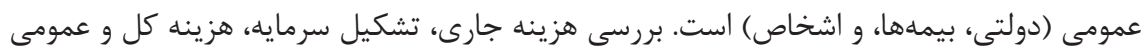

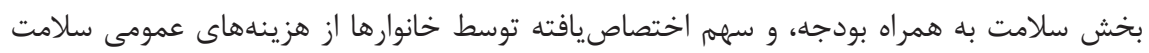

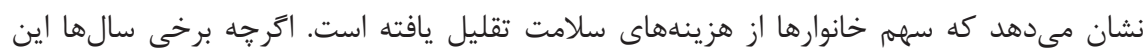

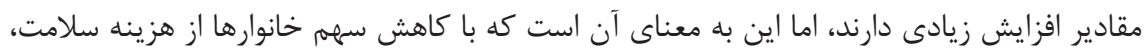


سهمم بخش عمومى افزايش مىيابد. افزايش سهم بخش عمومى، افزايش هزينه نهايى بخش عمومى، و در نتيجه هزينه نهايى اجتماعى را در يیى دارد. بررسى الكوى اقتصادسنجى عوامل موثر بر هزينههاى يزشكى شخصى نشان مى دهد كه اثر شاخص

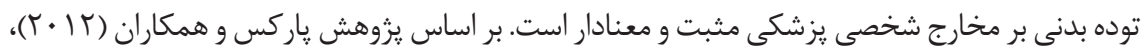
اثر شاخص توده بدنى بر مخارج شخصى يزشكى در كشورهايى مثبت است كه متوسط شاخص توده

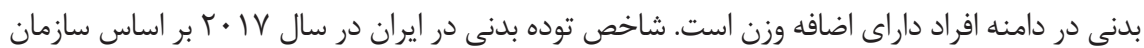

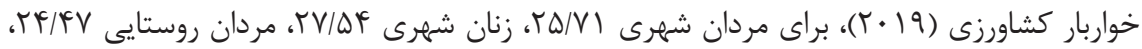

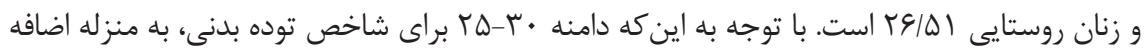
وزن است، بنابراين رابطه مثبت BMI با هزينههاى شخصى يزشكى منطقى به نظر مى بـرسد. متغيرهاى سن، تحصيلات، و فقر نيز اثرى مثبت بر هزينههاى شخصى يزشكى دارند كه در اين ميان، شاخص فقر

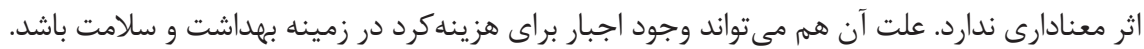

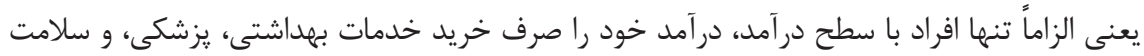

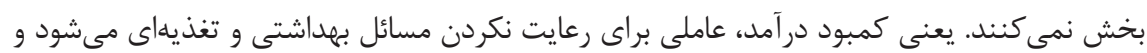
در نتيجه، هزينههاى شخصى يزشكى را افزايش مى دهد. داشتن سابقه بيمارى اثر مثبت و معنادار بر

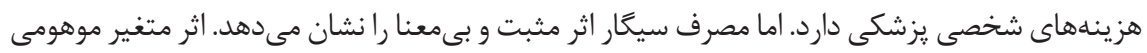

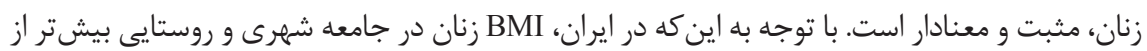
مردان است، به نظر مىرسد كه زنان بيشتر از مردان هزينه يزشكى دارند. با توجه به هدف اين يزوهش، ميزان بودجه تحميلى به بخش عمومى (دولتى، بيمهها، و اشخاص)

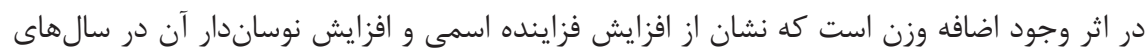

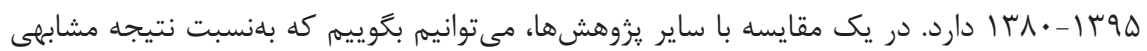

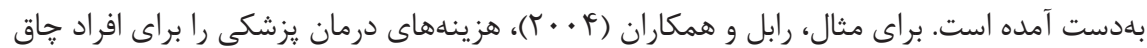

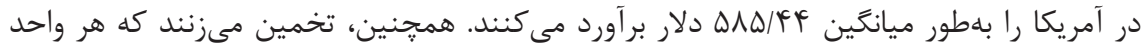
افزايش BMI، هزينههاى درمان را ب/ م/ درصد افزايش مىدهد كه به نتيجه ما بسيار نزديك است.

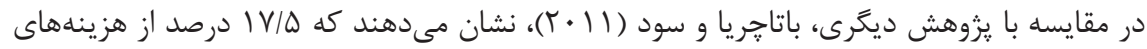
درمان در آمريكا، هزينه خارجى (عمومى و اجتماعى)، ناشى از خاقى است. اين هزينه، هزينه رفاهى

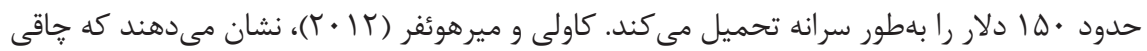

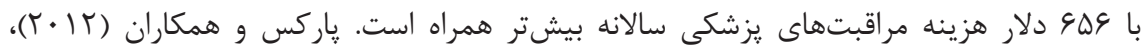


تخمين مىزنند كه افزايش ا واحدى شاخص توده بدنى براى هر بزرگسال در آمريكا، هزينههاى

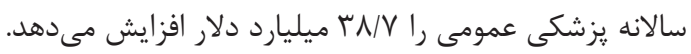
در نهايت، با توجه به اينكه، افزايش BMI، هزينههاى عمومى يزشكى را افزايش مى مدهد، مى توانيم سياستهايى را در جهت كاهش وزن، تناسب اندام، و در نتيجه سطح بالاترى از سلامتى تدوين نماييم تا علاوه بر كاهش رفاه ازدسترفته ناشى از اضافه وزن، بودجه اختصاصيافته به بخش بهداشت و درمان را كاهش دهيه. بنابراين، با ارائه راهكارهايى مانند ترويج فرهنگ تغذيه سالم و ارائه برنامه اجرايى تغذيه در بخش بهداشت بر اساس :زوهشهايى مانند جزايرى (IVDQ)؛ تبليغات

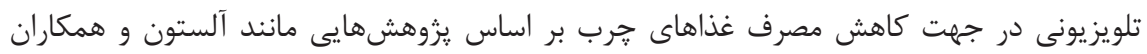

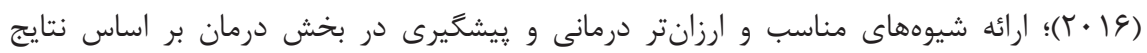

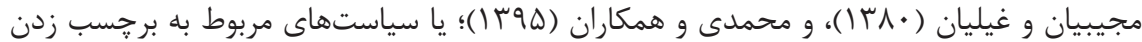

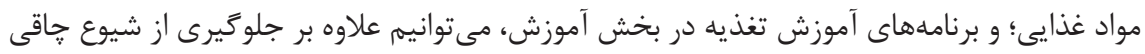
و اضافه وزن، روند افزايش وزن را كندتر كنيه.

\section{الف) فارسى}

اخوان طبيب، افشان؛ كليشادى، رويا؛ صدرى، غلامحسين؛ ثابت، بابك؛ طلوعى، حميدرضا، و بقايى، عبدالمهدى (بلى

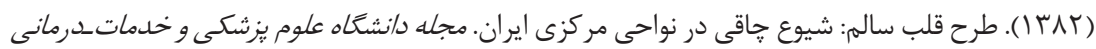

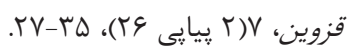

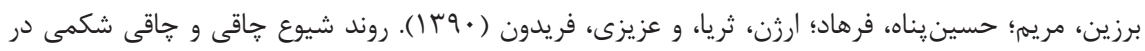

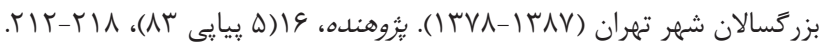

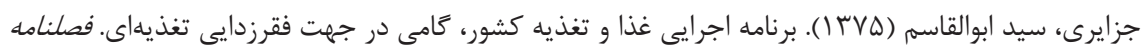

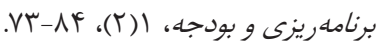

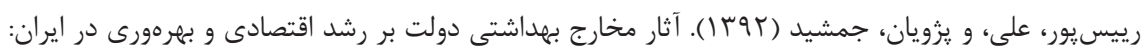

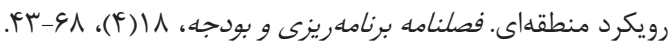

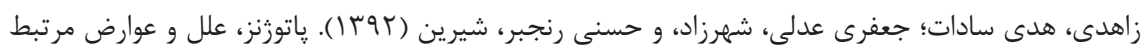




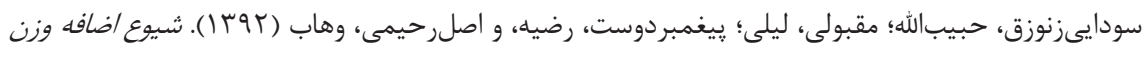

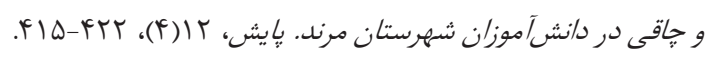

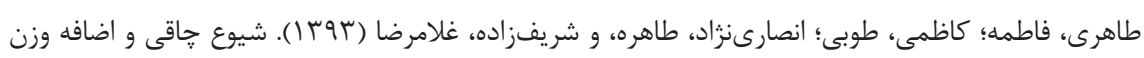

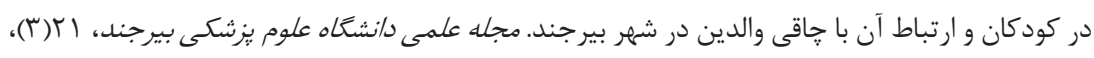

rrV - -rVG

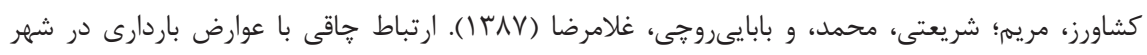

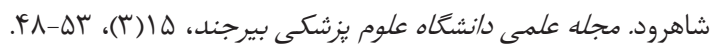

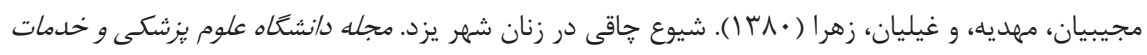

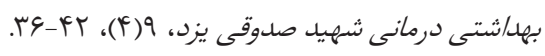

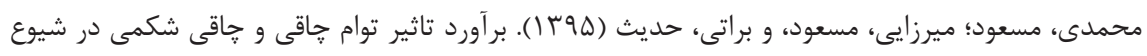

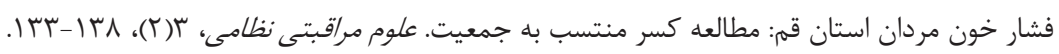

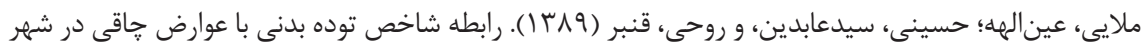

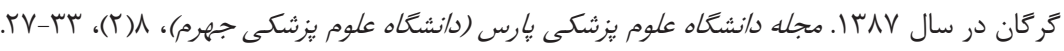

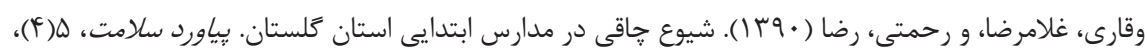
TF-rI

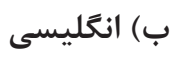

Allison, D. B., Zannolli, R., \& Narayan, K. (1999). The Direct Health Care Costs of Obesity in the United States. American Journal of Public Health, 89(8), 1194-1199.

Alston, J. M., MacEwan, J. P., \& Okrent, A. M. (2016). The Economics of Obesity and Related Policy. Annual Review of Resource Economics, 8(1), 443-465.

Bertakis, K. D., \& Azari, R. (2005). Obesity and the Use of Health Care Services. Obesity Research, 13(2), 372-379.

Bhattacharya, J., \& Bundorf, M. K. (2009). The Incidence of the Health Care Costs of Obesity. Journal of Health Economics, 28(3), 649-658.

Bhattacharya, J., \& Sood, N. (2006). Health Insurance and the Obesity Externality. Advances in Health Economics and Health Services Research, 17(1), 279-318.

Bhattacharya, J., \& Sood, N. (2011). Who Pays for Obesity? Journal of Economic Perspectives, 25(1), 139-158.

Burton, W. N., Chen, C.-Y., Schultz, A. B., \& Edington, D. W. (1999). The Costs of Body Mass Index Levels in an Employed Population. Statistical Bulletin (Metropolitan Life Insurance Company: 1984), 80(3), 8-14.

Cawley, J., \& Meyerhoefer, C. (2012). The Medical Care Costs of Obesity: An Instrumental Variables Approach. Journal of Health Economics, 31(1), 219-230. 
Finkelstein, E. A., Fiebelkorn, I. C., \& Wang, G. (2003). National Medical Expenditures Attributable to Overweight and Obesity: How Much, and Who's Paying? Health Affairs, 22(4), 219-226.

Finkelstein, E. A., Trogdon, J. G., Brown, D. S., Allaire, B. T., Dellea, P. S., \& Kamal-Bahl, S. J. (2008). The Lifetime Medical Cost Burden of Overweight and Obesity: Implications for Obesity Prevention. Obesity, 16(8), 1843-1848.

Finkelstein, E. A., Trogdon, J. G., Cohen, J. W., \& Dietz, W. (2009). Annual Medical Spending Attributable To Obesity: Payer-And Service-Specific Estimates: Amid Calls for Health Reform, Real Cost Savings are More Likely To Be Achieved Through Reducing Obesity and Related Risk Factors. Health Affairs, 28(Suppl1), 822-831.

Freebairn, J. (2010). Taxation and Obesity? Australian Economic Review, 43(1), 54-62.

Giraudo, S., Montero, J., Kaufmann, P., \& Grossman, B. (2016). Current Dietary Lipids Recommendations: Pros and Cons. Journal of Nutrition and Health Sciences, 3(4), 406-417

Kaufmann, R., \& Pontet-Ubal, N. (2019). The Challenge of Tackling the Obesity Economic Burden: The Case of Uruguay. Emerald Open Research, 1(11), 1-11.

Levi, J. (2010). F as in Fat: How the Obesity Crisis Threatens America's Future, 2010: Trust for America's Health.

MacEwan, J. P., Alston, J. M., \& Okrent, A. M. (2014). The Consequences of Obesity for the External Costs of Public Health Insurance in the United States. Applied Economic Perspectives and Policy, 36(4), 696-716.

NCD Risk Factor Collaboration. (2016). Trends in Adult Body-Mass Index in 200 Countries from 1975 to 2014: A Pooled Analysis of 1698 Population-Based Measurement Studies with 19· 2 Million Participants. The Lancet, 387(10026), 1377-1396.

Parks, J. C., Alston, J. M., \& Okrent, A. M. (2012). The Marginal External Cost of Obesity in the United States. RMI-CWE Working Paper Number 1201

Parks, J. C., Alston, J. M., \& Okrent, A. M. (2013). The External Health-Care Cost of Obesity in the United States. RMI-CWE Working Paper Number 1304

Raebel, M. A., Malone, D. C., Conner, D. A., Xu, S., Porter, J. A., \& Lanty, F. A. (2004). Health Services Use and Health Care Costs of Obese and Nonobese Individuals. Archives of Internal Medicine, 164(19), 2135-2140.

Sturm, R. (2002). The Effects of Obesity, Smoking, and Drinking on Medical Problems and Costs. Health Affairs, 21(2), 245-253.

Trogdon, J., Finkelstein, E. A., Hylands, T., Dellea, P., \& Kamal-Bahl, S. (2008). Indirect Costs of Obesity: A Review of the Current Literature. Obesity Reviews, 9(5), 489-500.

Wang, Y. C., McPherson, K., Marsh, T., Gortmaker, S. L., \& Brown, M. (2011). Health and Economic Burden of the Projected Obesity Trends in the USA and the UK. The Lancet, 378(9793), 815-825.

Wolf, A. M., \& Colditz, G. A. (1998). Current Estimates of the Economic Cost of Obesity in the United States. Obesity Research, 6(2), 97-106. 